\title{
MHD Boundary Layer Flow over a Stretching Sheet: A New Stochastic Method
}

\author{
Hakeem Ullah $\left(\mathbb{D},{ }^{1}\right.$ Imran Khan, ${ }^{1}$ Mehreen Fiza, ${ }^{1}$ Nawaf N. Hamadneh ${ }^{(D)}{ }^{2}$ \\ M. Fayz-Al-Asad (D), ${ }^{3}$ Saeed Islam, ${ }^{1}$ Ilyas Khan $\left(\mathbb{D},{ }^{4}\right.$ Muhammad Asif Zahoor Raja, ${ }^{5}$ \\ and Muhammad Shoaib ${ }^{6}$ \\ ${ }^{1}$ Department of Mathematics, Abdul Wali Khan University, Mardan 23200, KP, Pakistan \\ ${ }^{2}$ Department of Basic Sciences, College of Science and Theoretical Studies, Saudi Electronic University, \\ Madinah 11673, Saudi Arabia \\ ${ }^{3}$ Department of Mathematics, Bangladesh University of Engineering and Technology, Dhaka 1000, Bangladesh \\ ${ }^{4}$ Department of Mathematics, College of Science Al-Zulfi, Majmaah University, Al-Majmaah 11952, Saudi Arabia \\ ${ }^{5}$ Future Technology Research Center, National Yunlin University of Science and Technology, 123 University Road, Section 3, \\ Douliou, Yunlin 64002, Taiwan \\ ${ }^{6}$ Department of Mathematics, COMSATS University Islamabad, Attock Campus, Attock 43600, Pakistan
}

Correspondence should be addressed to M. Fayz-Al-Asad; fayzmath.buet@gmail.com

Received 17 March 2021; Revised 3 June 2021; Accepted 25 August 2021; Published 16 September 2021

Academic Editor: Giuseppina Colicchio

Copyright (C) 2021 Hakeem Ullah et al. This is an open access article distributed under the Creative Commons Attribution License, which permits unrestricted use, distribution, and reproduction in any medium, provided the original work is properly cited.

In this study, a new computing model is developed using the strength of feed-forward neural networks with the Levenberg-Marquardt scheme-based backpropagation technique (NN-BLMS). It is used to find a solution for the nonlinear system obtained from the governing equations of the magnetohydrodyanmic (MHD) boundary layer flow over a stretching sheet. Moreover, the partial differential equations (PDEs) for the MHD boundary layer flow over a stretching sheet are converting into ordinary differential equations (ODEs) with the help of similarity transformation. A dataset for the proposed NN-BLMM-based model is generated at different scenarios by a variation of various embedding parameters: Deborah number $(\beta)$ and magnetic parameter (M). The training (TR), testing (TS), and validation (VD) of the NN-BLMS model are evaluated in the generated scenarios to compare the obtained results with the reference results. For the fluidic system convergence analysis, a number of metrics, such as the mean square error (MSE), error histogram (EH), and regression (RG) plots, are utilized for measuring the effectiveness and performance of the NN-BLMS infrastructure model. The experiments showed that comparisons between the results of proposed model and the reference results match in terms of convergence up to E- 02 to E- 10 . This proves the validity of the NN-BLMS model. Furthermore, the results demonstrated that there is a decrease in the thickness of the boundary layer by increasing the Deborah number and magnetic parameter. The importance of the experiment can be seen due to its industrial applications such as MHD power generation, MHD generators, and MHD pumps.

\section{Introduction}

The boundary layer flow of an incompressible liquid over a stretching sheet is common in many engineering and industrial processes. The field has attracted researchers in the last few decades. The boundary layer flow has major applications in industries such as in the aerodynamic extrusion of a polymer sheet from a die, hot rolling, the cooling of an infinite metallic plate in a cooling bath, the boundary layer along a liquid film in condensation process, and glass-fiber production [1-3]. Many metallurgical processes contain the cooling of continuous filaments by drawing them through a quiescent fluid. The mechanical properties of the product depend on the rate of cooling and the stretching. Sakiadis $[4,5]$ pioneered the study on the stretching sheet and boundary layer flow. The boundary layer flow over a 
continuous stretching sheet with constant speed was studied with various conditions. Cran [6] studied the closed form solution of the boundary layer flow with the stretching sheet. Gupta and Gupta [7] investigated the magnetic field effects on the boundary layer flow with the stretching sheet. Anderson [8] studied the porosity effects on the stretching sheet with the conducting particles of fluid. Ariel [9] investigated the combined effect of viscoelasticity and magnetic field on the Cranes problem. Since stretching sheet can occur in a variety of ways, the flow through the stretched sheet does not always need to be of two sizes. If the extension is radial, it can be three. A flat surface of three stretches and the same width was examined by Wang [10]. Brady and Acrivos [11] monitor the flow inside the channel or tube and the Wang flow outside the performing tube [12]. Wang [13] and Usha and Sidharan [14] tested the unstable stretching sheet. Ariel et al. [15] used HPM and expanded HPM to obtain a solution for analysis in the axisymmetric flow across the flat layer of the boundary layer flow. A noniterative solution for MHD flow of the boundary layer flow over a stretching sheet was provided by Ariel [16]. Magnetohydrodynamics (MHD) is the study of the interaction of electromagnetic conditions with the transfer of liquid heat. The flow of conducting fluids is important in many areas of science and engineering, such as MHD power generation, MHD generators, and MHD pumps. Recently, many researchers worked on boundary layer flow [17-25]. They considered the MHD effects of different boundary layer flow with the stretching sheet. Recently, many scientists studied the effects of MHD and heat transfer on various boundary layer flows for different parameters [26-31]. All these numerical methods are applied to solve the problem in different scenarios, and each has advantages and disadvantages. Although stochastic numerical computing based on artificial intelligence has been developed to solve stiff nonlinear problems, these solvers are not yet used to analyze this boundary layer flow model's governing system. Stochastic numerical computing solvers are generated basically by taking advantage of computing based on artificial neural networks (ANN) modeling and its optimization of the process to solve different problem systems of ordinary or partial differential equations. There are many modern applications of stochastic numerical computing solvers in various branch of sciences such as thermodynamics, astrophysics, offline circuits, atomic physics, MHD, plasma physics, fluid dynamics, electromagnetics, nanotechnology, bioinformatics, electricity, energy and finance, and random matrix theory [31-48]. Inspired from these facts, the authors study to explore and incorporate the soft computing architectures as an alternative, precise, and feasible computational approaches for solving the fluid mechanics systems associated with the boundary layer flow. The main purpose of this study is to analyze the effect of physical parameters associated with the boundary layer flow system under the influence of the magnetic effect by using an intelligent computing technique based on the Levenberg-Marquard algorithm, whereas, Levenberg-Marquard (LM) inherits accuracy and fastness from the Newton method. Moreover, it also has the steepest descent method convergence capability [42]. Optimization of the data used in the training of deep networks is a very important parameter for the prediction performance of the model [49]. Some of the recent development in AI methods can be seen [50-55]. Some structures of our discussion are noted as follows.

The key aspects of the proposed computing paradigm are given as follows:

A new application based on artificial intelligence-based computing using neural network backpropagated with Levenberg-Marquard is implemented to study the MHD boundary layer flow with the stretching sheet

The dataset for the NN-BLMS is generated for variations of Deborah and magnetic parameters through the OHAM

The governing equations are transformed from a set of PDEs into ODE by using similarity transformation

The processing of NN-BLMS means training, testing, and validation in employed on the boundary layer flow model for different scenarios to obtain the approximate solution and comparison with reference results

The convergence analysis based on mean square, error histogram, and regression plots are employed to ensure the performance of NN-BLMS for the detailed analysis of the boundary layer flow model

The mathematical modeling of the boundary layer flow model has been presented in Section 2. The method for the analysis of the MHD boundary layer flow over a stretching sheet has been discussed in Section 3. The numerical and graphical results with discussion and comparison for the MHD boundary layer flow over a stretching sheet through the proposed technique NN-BLMS with numerical reference results are given in Section 4. Finally, concluding remarks for the study on the proposed methodology for the MHD boundary layer flow over a stretching sheet is presented in Section 5.

\section{Mathematical Formulation of the Boundary Layer Flow Model}

Consider a viscous fluid on a stretching sheet. Initially, both the sheet and the fluid are at rest. The plate is stretched in the $x$ direction, and fluid starts flowing uniformly. A uniform magnetic field $B(x)$ is applied perpendicular to the flow. The flow is considered steady and incompressible. A boundary layer is originated as shown in Figure 1.

The fundamental equations in the form of continuity and momentum equations are given as [17]

$$
\begin{gathered}
\frac{\partial u}{\partial x}+\frac{\partial v}{\partial y}=0 \\
u \frac{\partial u}{\partial x}+v \frac{\partial v}{\partial y}=-v \frac{\partial^{2} u}{\partial y^{2}}-\frac{\sigma B^{2}}{\rho} u
\end{gathered}
$$

Using the boundary conditions (BCs), 


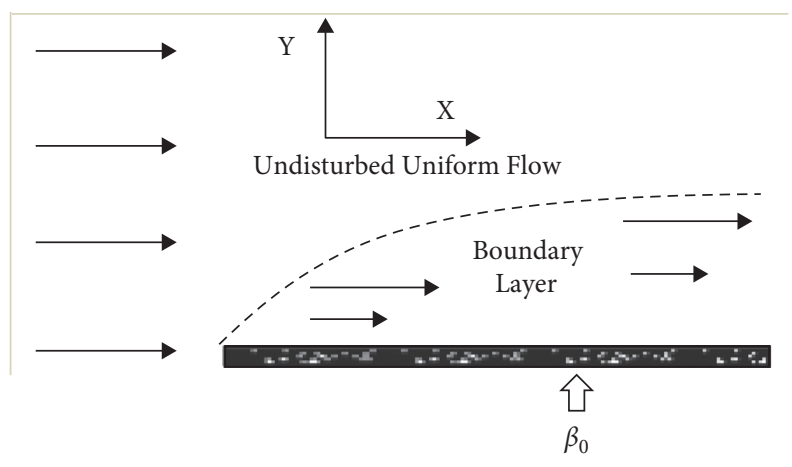

Figure 1: Sketch of the flow problem.

$$
\begin{gathered}
u(x, 0)=c x^{n}, \\
v(x, 0)=0, \\
u(x, \infty)=0 .
\end{gathered}
$$

In order to reduce the governing equation into boundary value problem using the following similarity transformation [17],

$$
\begin{aligned}
u(x, y) & =u x^{k} f^{\prime}(\eta), \\
\eta & =y \sqrt{\frac{c(k+1)}{2 v}} x^{k-1 / 2} y, \\
v(\eta) & =-\sqrt{\frac{c(k+1)}{2}} x^{k-1 / 2}\left[f(\eta)+\frac{(k-1)}{(k+1)} \eta f^{\prime}(\eta)\right] .
\end{aligned}
$$

We obtain

$$
\begin{array}{r}
\frac{\mathrm{d}^{3} f}{\mathrm{~d} \eta^{3}}+f \frac{\mathrm{d}^{2} f}{\mathrm{~d} \eta^{2}}-\beta\left(\frac{\mathrm{d} f}{\mathrm{~d} \eta}\right)^{2}-M \frac{\mathrm{d} f}{\mathrm{~d} \eta}=0 \\
f(0)=0, f^{\prime}(0)=1, f^{\prime}(\infty)=0
\end{array}
$$

where $\beta=2 n / 1+n$ and $M=2 \sigma \beta_{o}{ }^{2} / \rho c(1+n)$.

\section{Solution Procedure}

The single neural network model for the proposed NNBLMS is shown in Figure 2. The general procedure of NNBLMS presented step by step is given in Figure 3. NN-BLMS is accomplished with the help of nftool in MATLAB by setting for fitting the neural network tools with backpropagation of Levenberg-Marquardt executing the weight of neural networks. It is clear from the analysis that the NNBLMS is implemented for the fluidic model MHD boundary layer flow over a stretching sheet by setting the values of one parameter $\beta$ and treating the other physical parameters $M$ as fixed. In the same fashion, the other parameters are changeable, and a total of three scenarios and each scenario have three cases. The proposed NN-BLMS is performed for four scenarios by varying beta and magnetic parameters for $f$ and $f$, with different cases for each scenario as shown in Table 1. For using the NN-BLMS, we used the step size of
0.03 between the intervals of the problem by using the OHAM. We select $80 \%, 10 \%$, and $10 \%$ for testing, training, and validation, respectively, for 301 data input points for the $f$ values randomly. TR is used for the assembly of a result assembled on MSE, and VD data is used for representing $\mathrm{NN}$, while TT data is used to test the PF of random contributions.

The NN-BLMS-based computing paradigm with 1-layer structure of neural networks (hidden and output) is shown in Figure 4.

\section{Analysis of Results}

The proposed NN-BLMS is used for cases 1 and 3 of all scenarios. Figures 4 and 5 show the results of state and performance, whereas fitting the solution is given in Figures 6-13 . EH plots are given in Figure 14, and the regression analysis is given in Figures 15-22 of the MHD boundary layer flow over a stretching sheet. For cases 1 and 3 of all scenarios, MSE assembly of TR, VLD, and TS processes are given in Figures 4(a)-4(h). One can see that the best PF has been achieved at $6,153,3,12,479,391,440$, and 611 epochs with MSE around $3.4885 \times 10^{-5}, 1.3071 \times 10^{-9}$ $4.295 \times 10^{-6}, \quad 7.7450 \times 10^{-6}, \quad 1.5272 \times 10^{-7}, \quad 5.3331 \times 10^{-7}$, $3.5795 \times 10^{-8}$, and $3.0441 \times 10^{-7}$, respectively, given in Figure 4. Appropriate values for GD and step $\mathrm{Mu}$ size of backpropagation are $4.2526 \times 10^{-04}, \quad 9.9537 \times 10^{-08}$, $1.678 \times 10^{-04}, \quad 2.3718 \times 10^{-5}, \quad 9.9666 \times 10^{-8}, \quad 9.9689 \times 10^{-8}$, $9.9879 \times 10^{-8}$, and $9.983 \times 10^{-08}$ and $10^{-09}, 10^{-11}, 10^{-08}, 10^{-07}$, $10^{-08}, 10^{-09}, 10^{-09}$, and $10^{-08}$ as shown in Figure 5. From these figures and results, it is clearly demonstrated that the NN-BLMS is accurately and reliably convergent in each case of MHD boundary layer flow over a stretching sheet. For cases 1 and 3 of all scenarios of MHD boundary layer flow over a stretching sheet model, the effectiveness of NN-BLMS is scrutinized with the reference numerical results of OHAM along with the error dynamics given in Figures 6-13. The maximum error achieved in the testing, performance, and validation by the proposed NN-BLMS is less than $3.5 \times 10^{-04}$, $0.8 \times 10^{-03}, 0.2 \times 10^{-03}, 0.4 \times 10^{-03}, 3.5 \times 10^{-04}, 0.8 \times 10^{-03}$, $0.3 \times 10^{-03}$, and $1.4 \times 10^{-03}$ as given in Figures 6-13. Error variability is also assessed with $\mathrm{EH}$, and the results are given in Figures 14(a)-14(f). Error variability is also assessed with error histogram for each input point, and the results are 


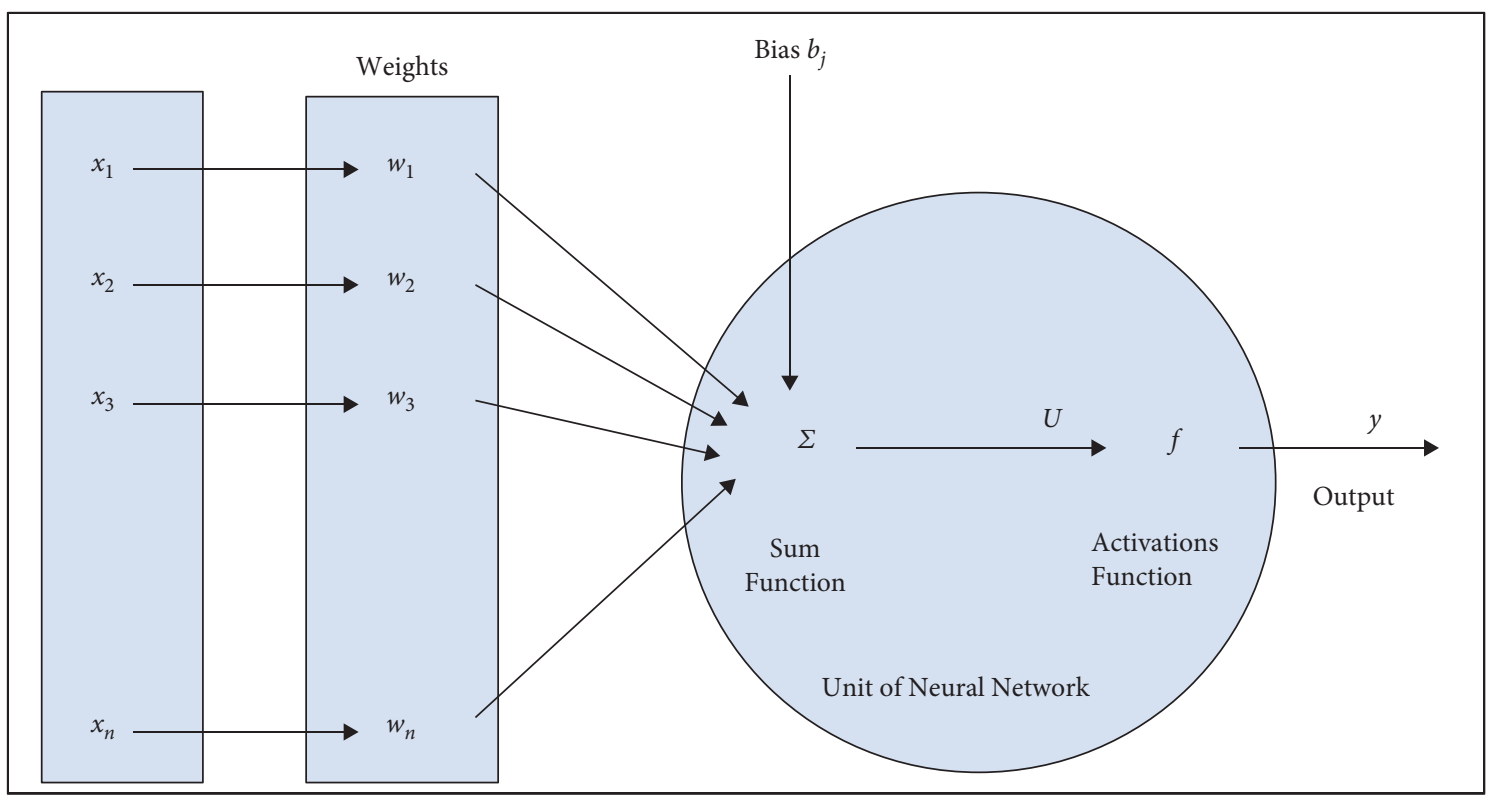

FIgURE 2: The structure of a single neural network model.

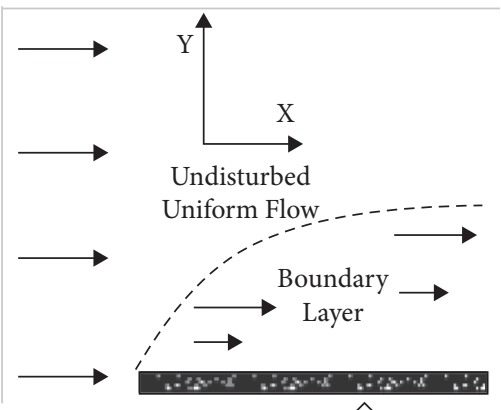

$$
\begin{gathered}
\frac{d^{3} f}{d \eta^{3}}+f \frac{d^{2} f}{d \eta^{2}}-\beta\left(\frac{d f}{d \eta}\right)^{2}-M \frac{d f}{d \eta}=0, \\
f(0)=0, f^{\prime}(0)=1, f^{\prime}(\infty)=0
\end{gathered}
$$

$$
\text { where } \beta=\frac{2 n}{1+n}, M=\frac{2 \sigma \beta_{0}^{2}}{p c(1+n)}
$$

(a)

(b)

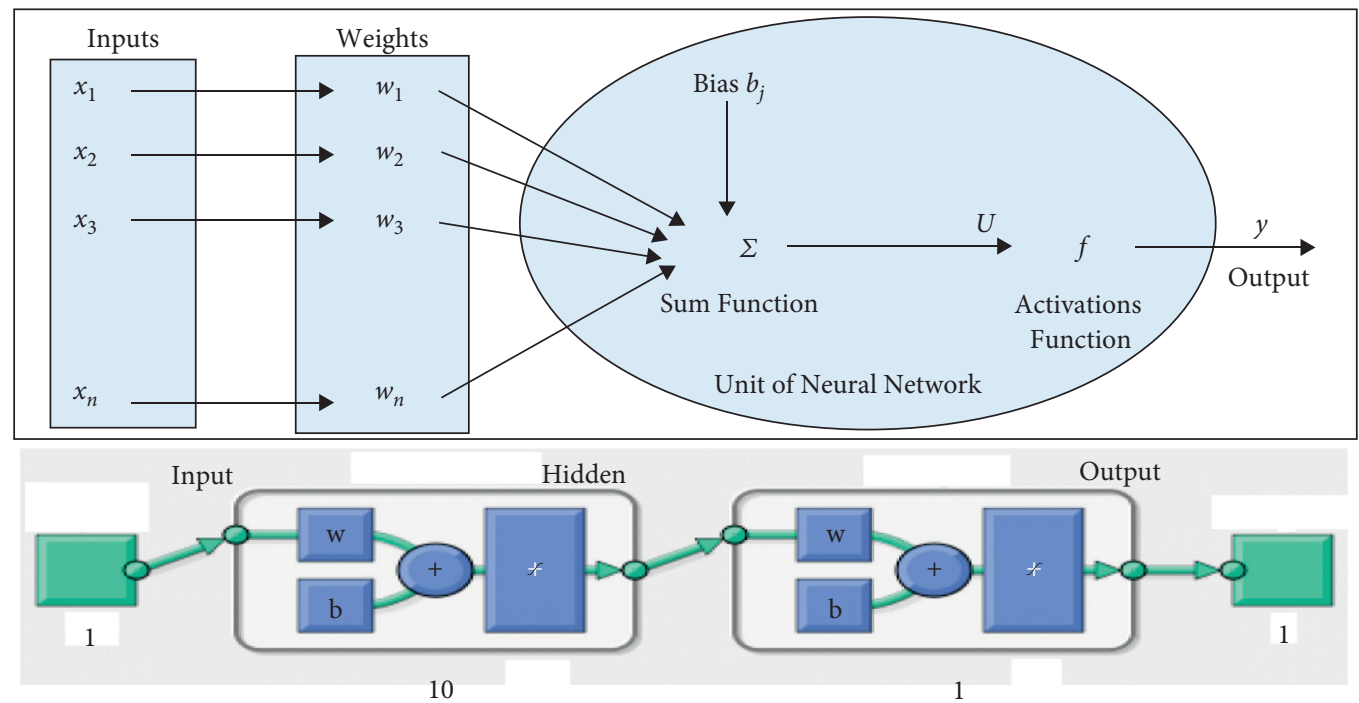

(c)

Figure 3: Continued. 


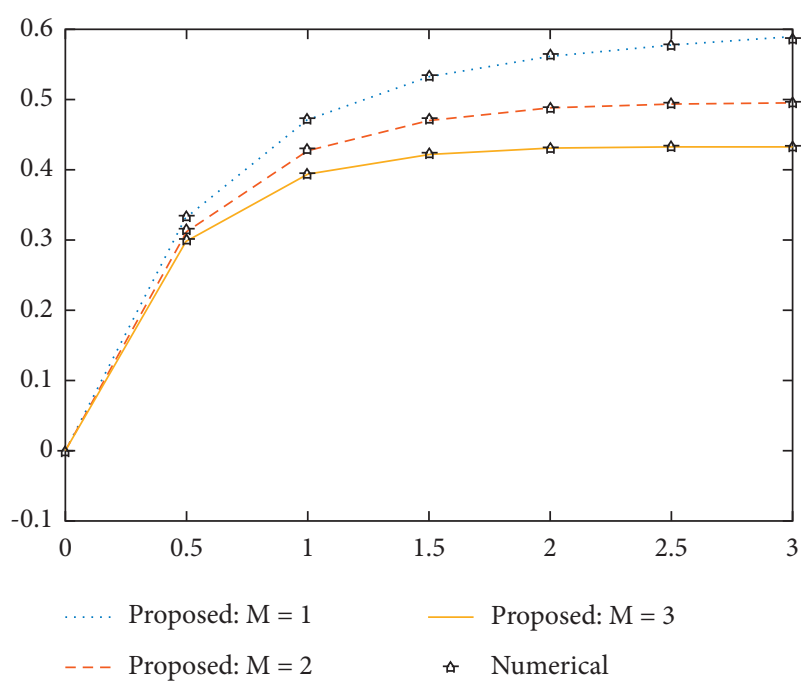

(d)
Analysis of assessment

1. Mean square error based fitness

2. Absolute error analysis

3. State transition analysis

4. Error histograms

5. Regression studies

FIgURE 3: The methodology workflow of ANN-BLMS for MHDFF BLPSS: (a) sketch of the flow problem, (b) problem formulation, (c) developed intelligent computing network model, (d) results, and (e) comparative analysis.

TABLE 1: Description of scenarios along with the cases for MHD boundary layer flow over a stretching sheet: physical parameters of interest.

\begin{tabular}{|c|c|c|c|}
\hline Scenario & Case & $\beta$ & $M$ \\
\hline \multirow{3}{*}{ For $f 1$} & 1 & 1 & 1 \\
\hline & 2 & 2 & 1 \\
\hline & 3 & 3 & 1 \\
\hline \multirow{3}{*}{2} & 1 & 1 & 1 \\
\hline & 2 & 1 & 2 \\
\hline & 3 & 1 & 3 \\
\hline \multirow{3}{*}{ For $f^{\prime} 3$} & 1 & 1 & 1 \\
\hline & 2 & 2 & 1 \\
\hline & 3 & 3 & 1 \\
\hline \multirow{3}{*}{4} & 1 & 1 & 1 \\
\hline & 2 & 1 & 2 \\
\hline & 3 & 1 & 3 \\
\hline
\end{tabular}

given in Figure 14. The maximum error achieved is less than $5.5 E-4,-9.8 E-5,-3.7 E-5,-4.3 E-3,-4 E-6,5.02 E-6$, $2.94 E-6$, and $-4.1 E-5$ in all cases of the MHD boundary layer flow over a stretching sheet. The investigation over regression is given with the help of correlation studies. The results of RG are given in Figures 15-22. The study of correlation is piloted by regression studies. The results of regression for each scenario are around unity, and the values of correlation $R$ are reliable, which mean that testing, training, and validations are accurately modeled to perform the NN-BLMS. Moreover, for all three cases of each scenario of the MHD boundary layer flow over a stretching sheet, the convergence attains parameter in terms of PF, MSE, performed period, time of performance, and backpropagation measures which are prescribed in Table 2 for all cases of each scenario separately. The PF is approximately $10-09,10-10$ to $10-09,10-09,10-08,10-08$, and 10-08 for all scenarios with 1 and 3 cases of MHD boundary layer flow over a stretching sheet. These results show the stable PF of NN-BLMS for each case of MHD boundary layer flow over a stretching sheet model. The effects of the physical parameters on the velocity profile based on the results of NN-BLMS are given in Figures 23(a)-26(a) . The variation (rise) of the physical parameter Deborah number $\beta$ results to decrease the velocity profile. Initially, the effect of $\beta$ is very small in interval $[0$, 0.5 ], and the effect of increasing $\beta$ is very clear in 0.5 to 3 causing decrease in the velocity profile as shown in Figure 23(a). Similarly, the effect of magnetic parameters $M$ on velocity profile is shown in Figures 24(a). It is observed that, by increasing the values of $M$, a decrease in velocity profile (boundary layer thickness) is observed. These parameters have low effect near the origin and have a clear impact away from origin. By increasing the physical parameters $\beta$ and $M$, a decrease in the velocity profiles is observed. It is due to the fact that the parameters increase the opposing forces which turn to reduce the velocity profile. The effects of these parameters for the velocity profile $f^{\prime}$ are given in Figures 25(a) and 26(b). Again, increasing the opposite effects has been observed as shown in Figures 23(a) and 24(a). The NN-BLMS results are verified by comparing 

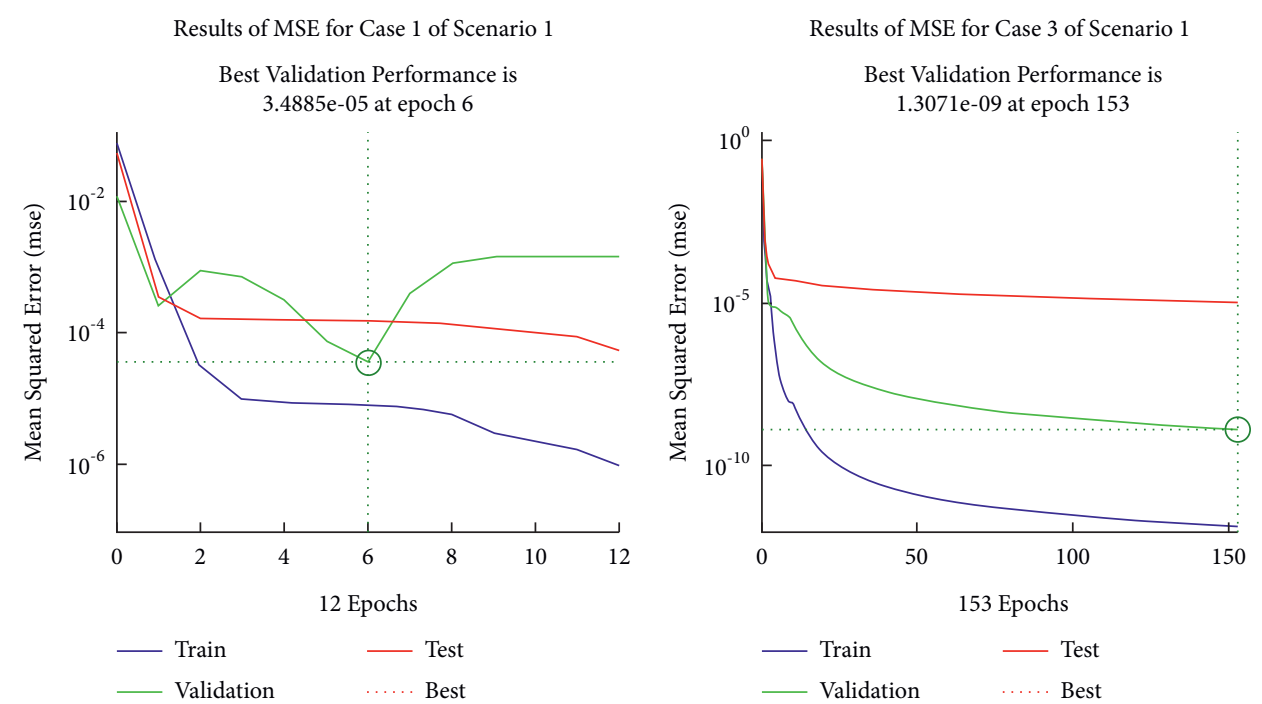

(a)

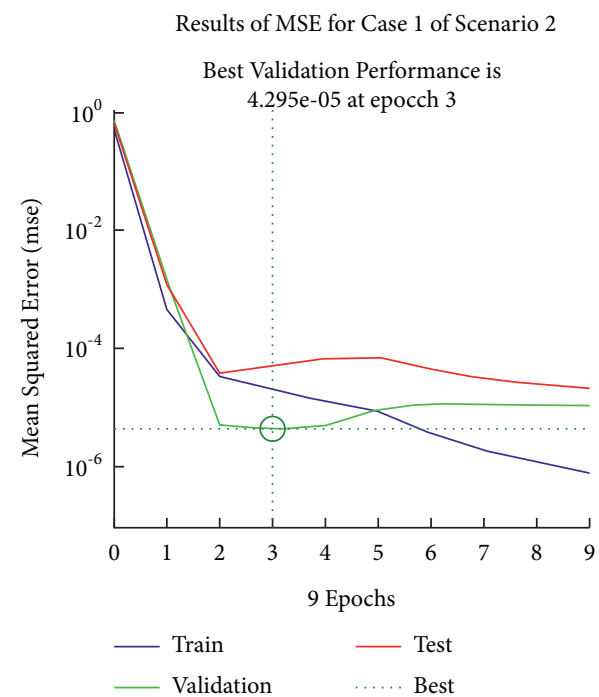

(c)

Results of MSE for Case 1 of Scenario 3

Best Validation Performance is 1.5272e-07 at epoch 479

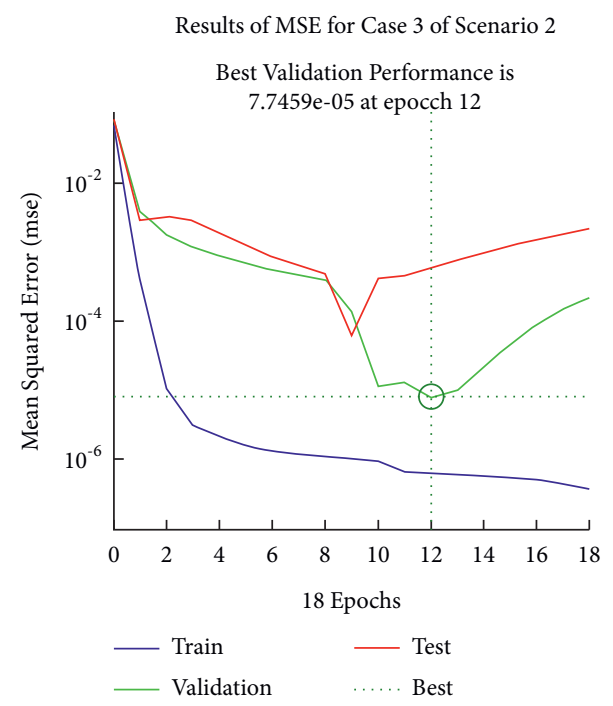

(d)

Results of MSE for Case 3 of Scenario 3

Best Validation Performance is 5.3331e-07 at epoch 391

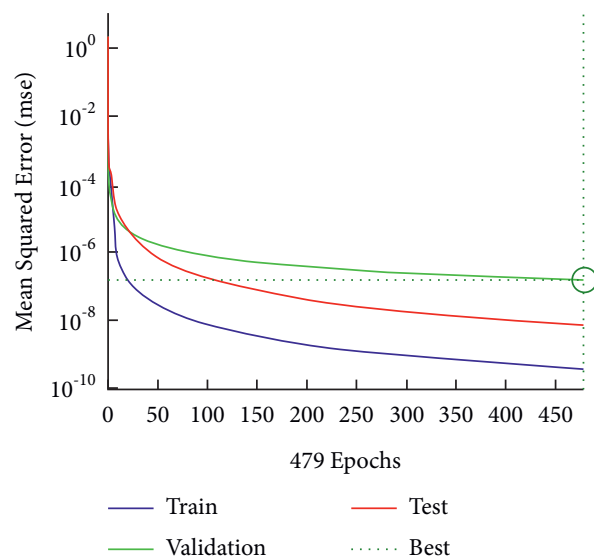

(e)

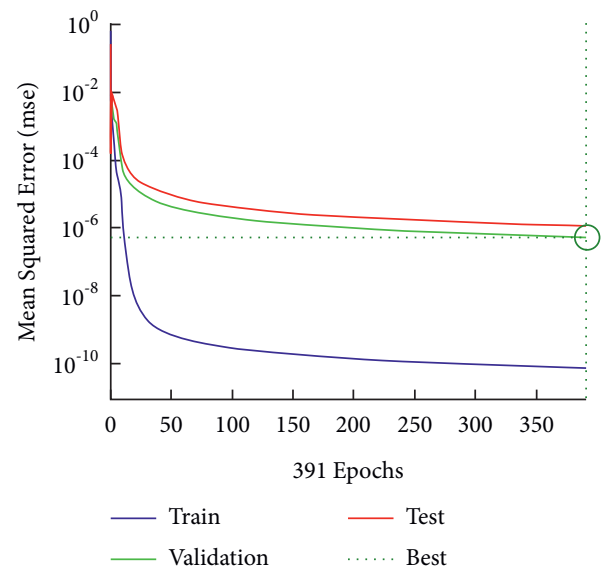

(f)

Figure 4: Continued. 


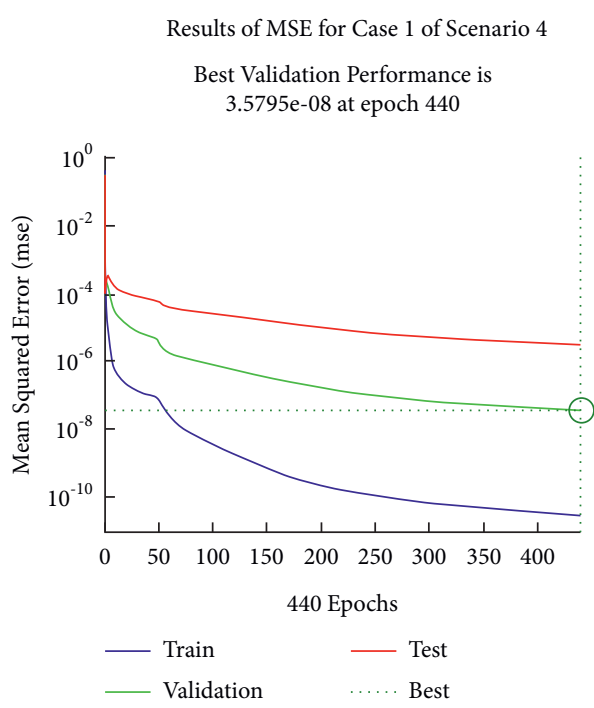

(g)

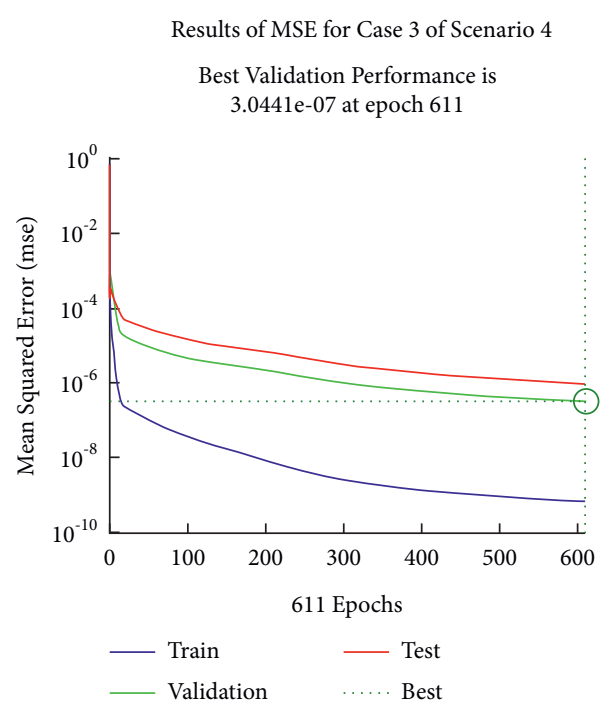

(h)

Figure 4: Performance of MSE for proposed NN-BLMS for solving MHD BLFSS.
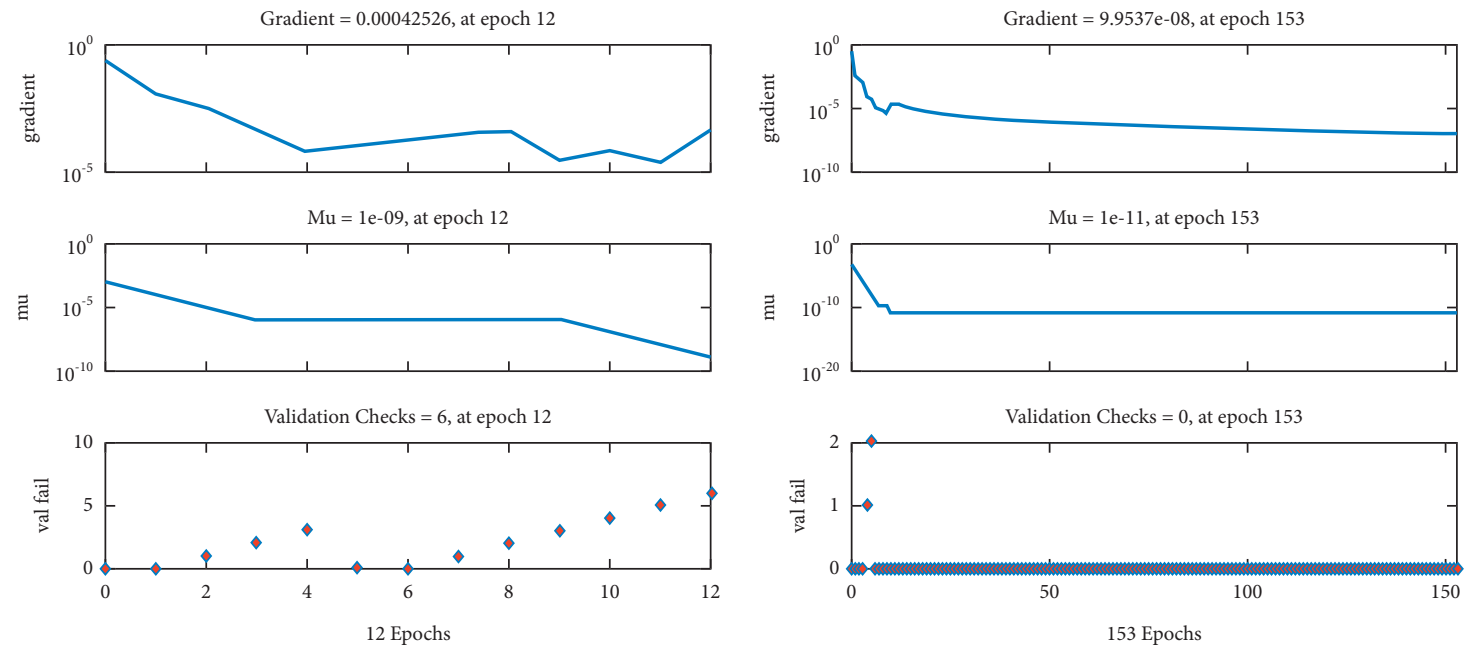

(a)

(b)
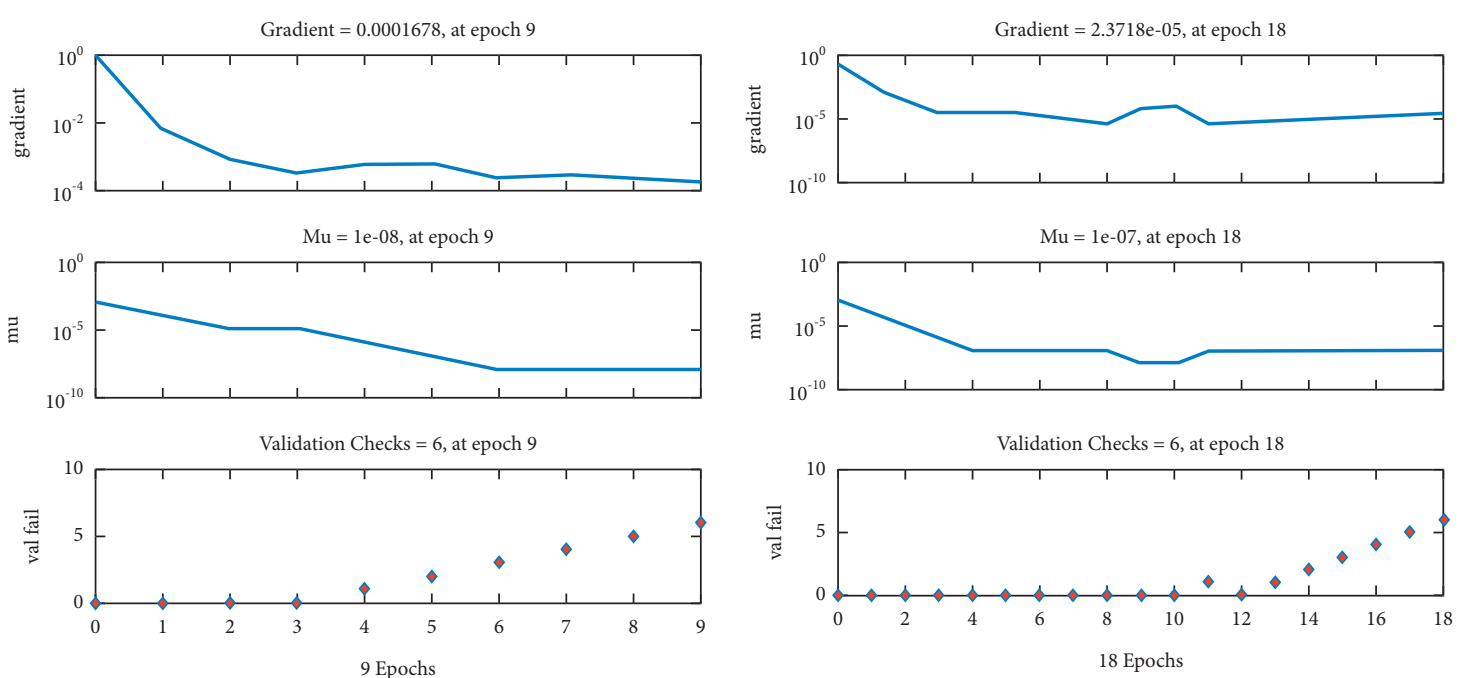

(c)

(d)

Figure 5: Continued. 

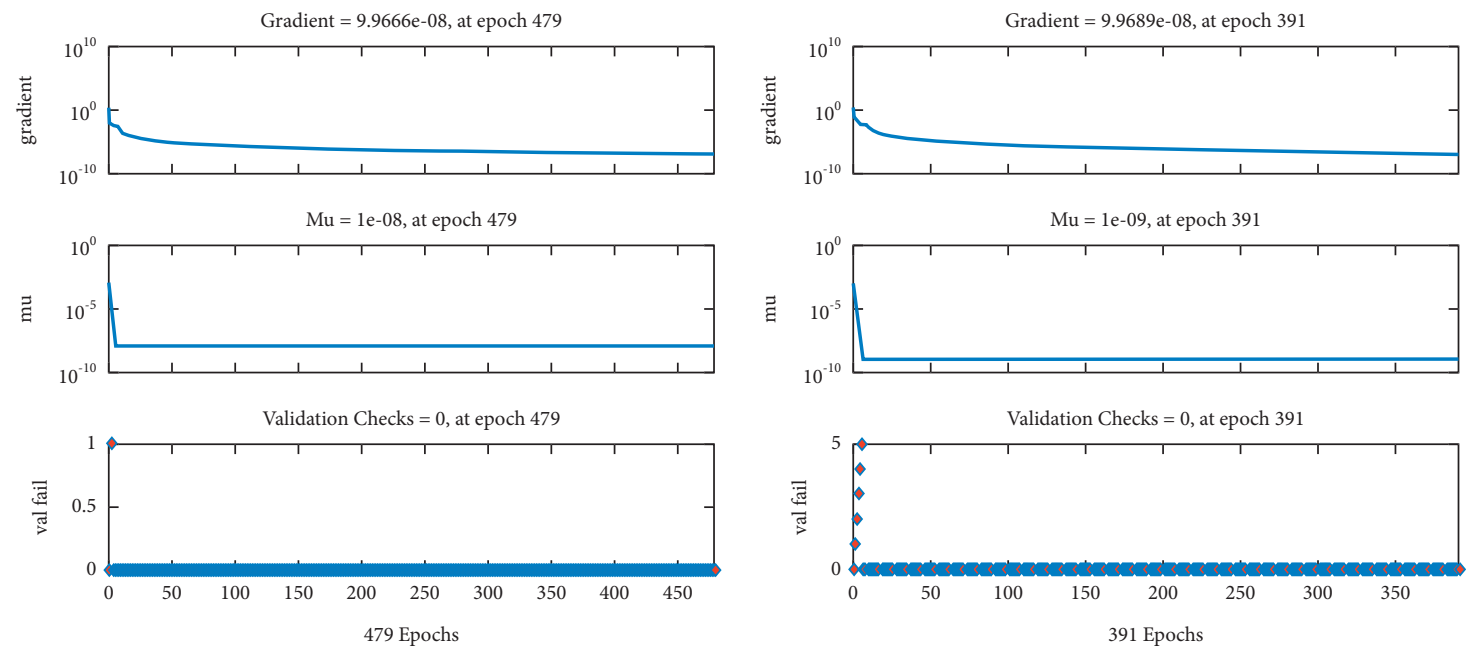

(e)

(f)
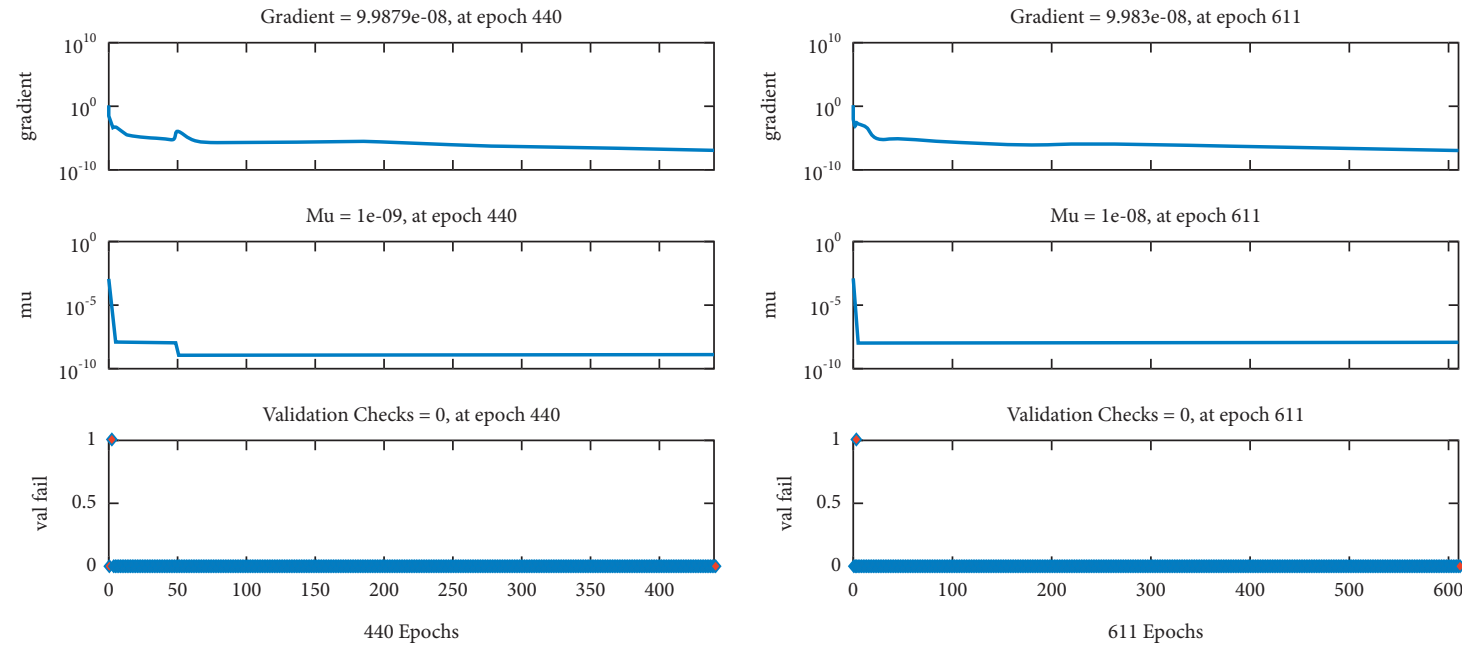

(g)

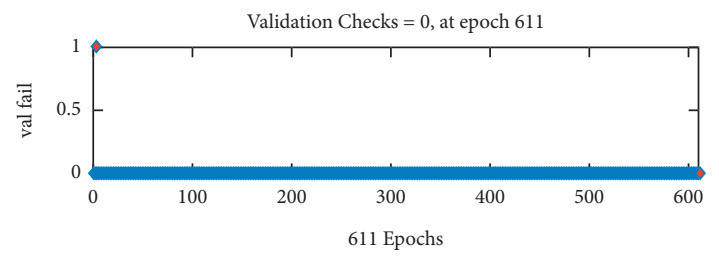

(h)

FIgURE 5: State transition dynamics of NN-BLMS for solving the MHD BLFSS.
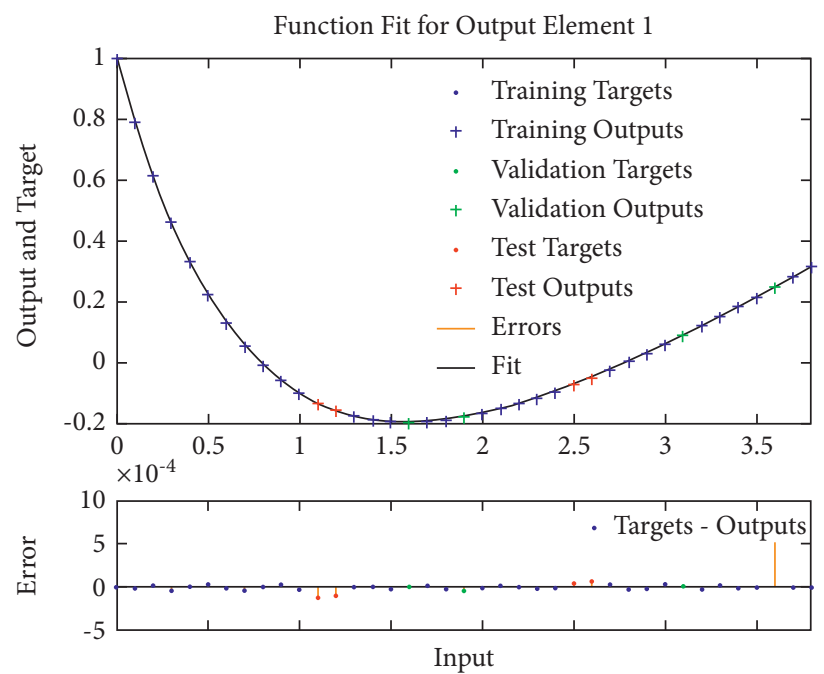

FIGURE 6: Comparison of NN-BLMS result with reference solution for case 1 of scenario 1 of MHD BLFSS. 

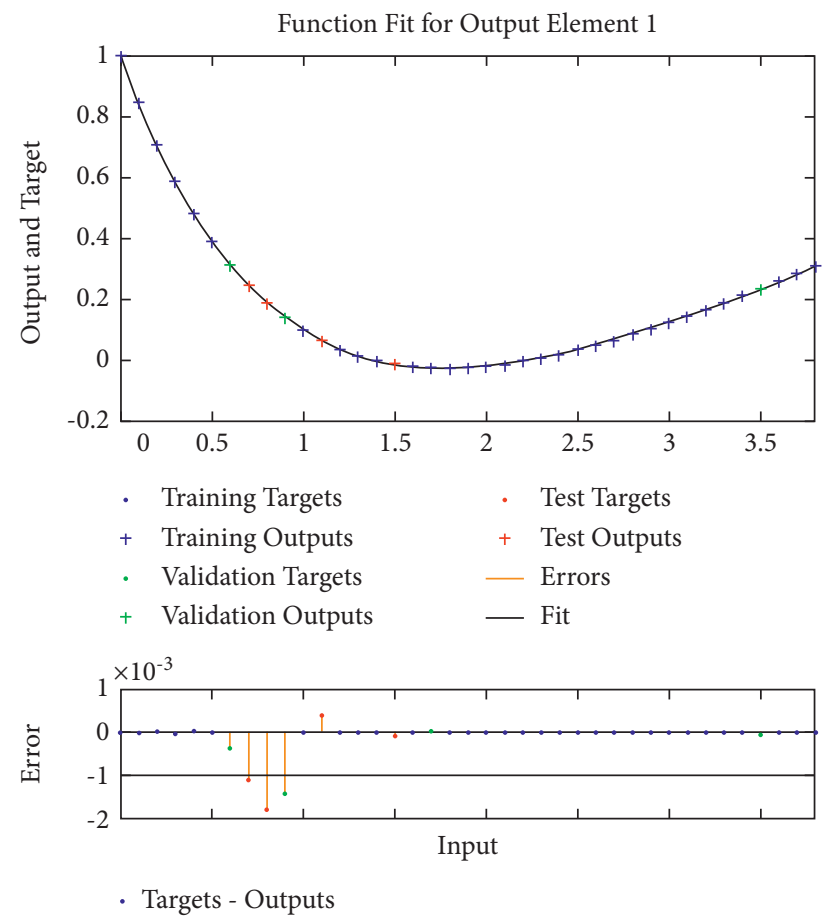

FIgURE 7: Comparison of NN-BLMS result with reference solution for case 3 of scenario 1 of MHD BLFSS.

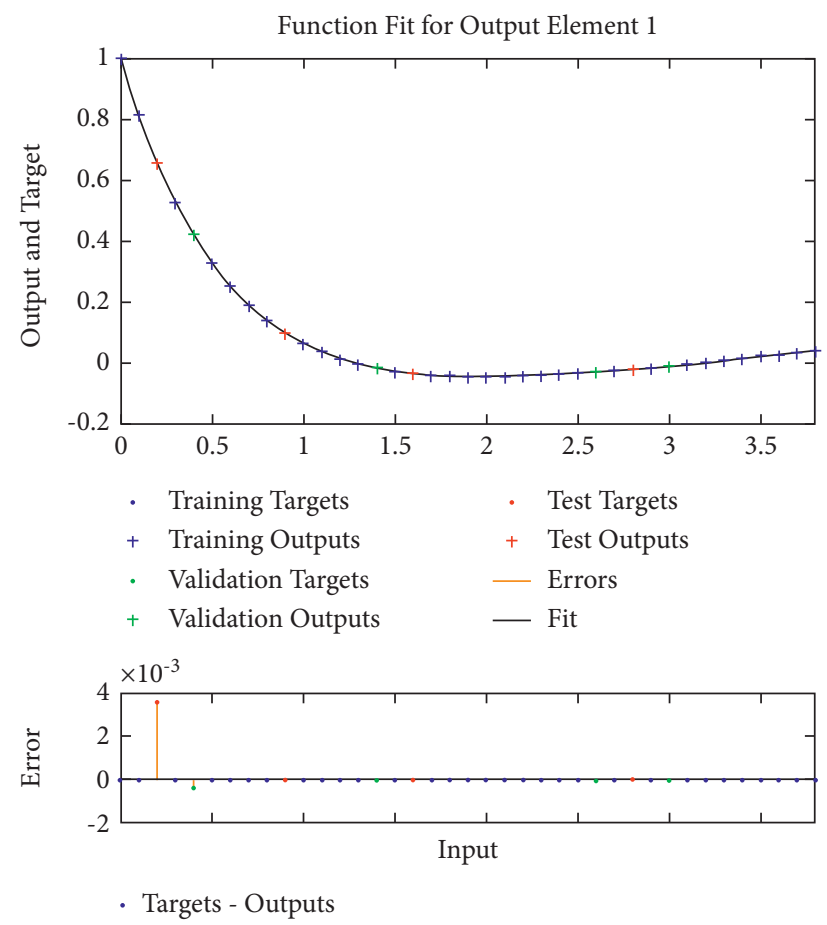

FIGURE 8: Comparison of NN-BLMS result with reference solution for case 1 of scenario 2 of MHD BLFSS.

the results with numerical, and hence, the validation of our method is proved. In the Figures 20(b), 21(b), and 22(b), the absolute errors (AE) are shown for all scenarios. In these figures, the $\mathrm{AE}$ is observed $10-04$ to $10-08,10-03$ to $10-06$,
$10-03$ to $10-06,10-03$ to $10-05$, and $10-05$ to $10-06$, respectively. These illustrations clearly indicate the performance of NN-BLMS for the solution of the fluid model. The $\mathrm{AE}$ further validates the accuracy and precision of the 

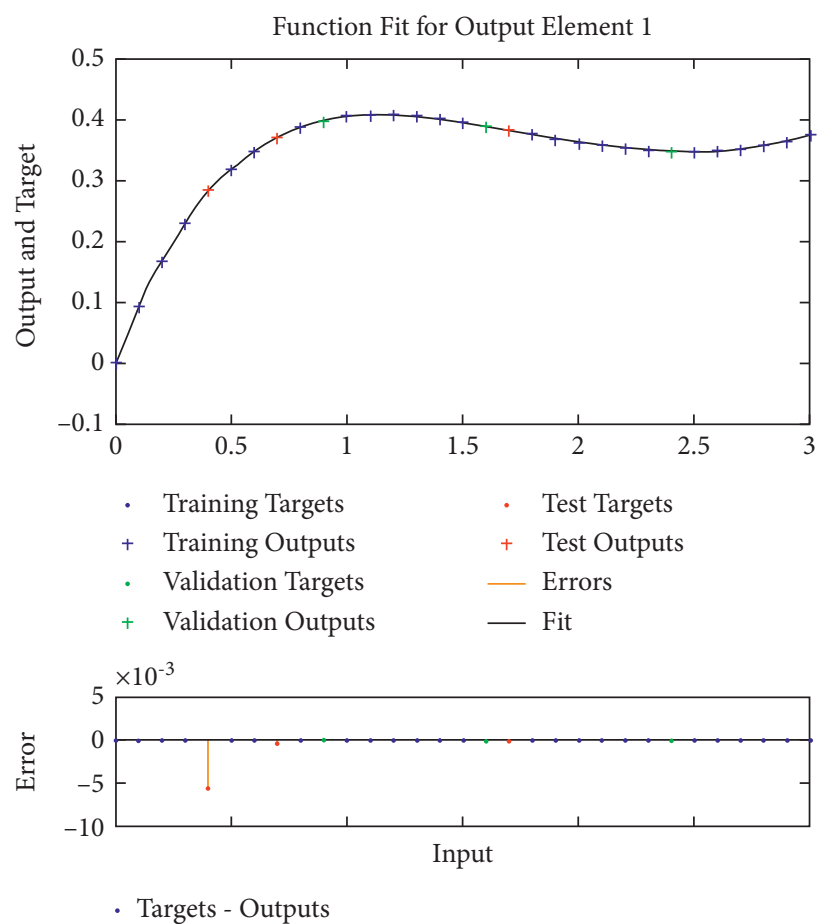

FIGURE 9: Comparison of NN-BLMS result with reference solution for case 3 of scenario 2 of MHD BLFSS.

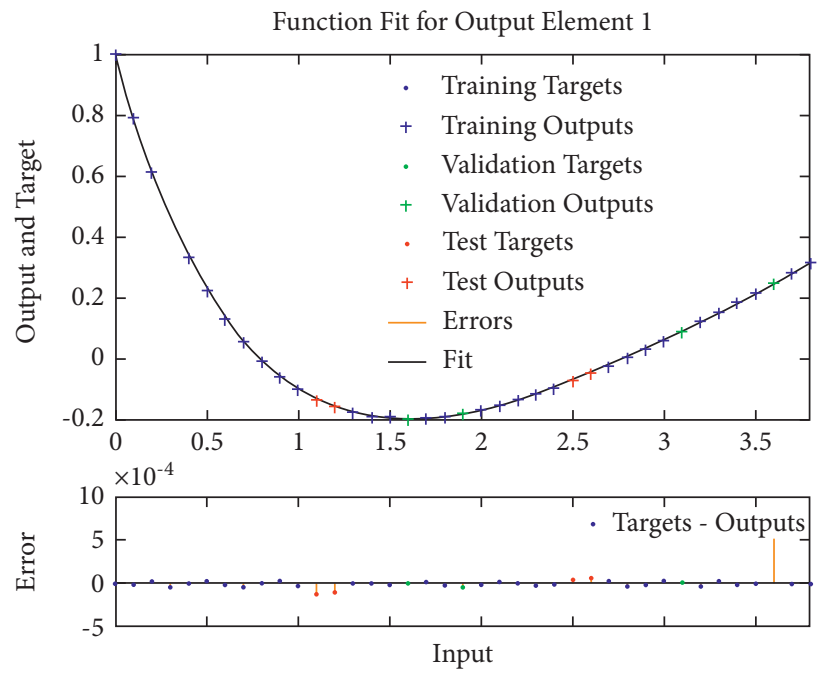

Figure 10: Comparison of NN-BLMS result with reference solution for case 1 of scenario 3 of MHD BLFSS. 


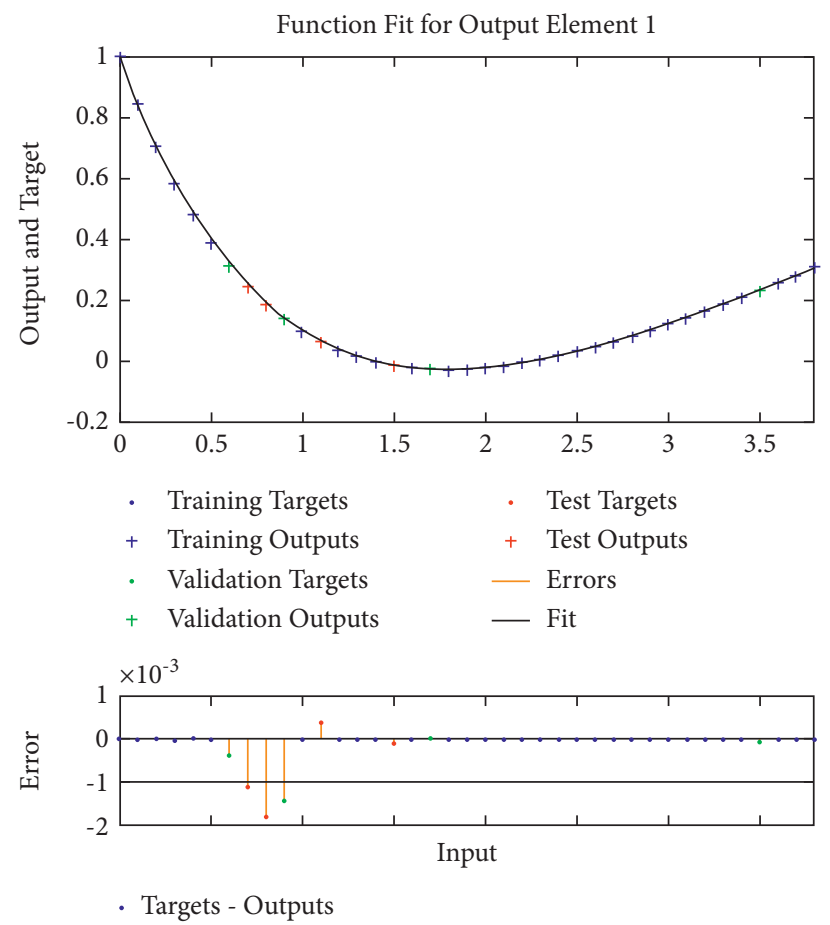

FIGURE 11: Comparison of NN-BLMS result with reference solution for case 3 of scenario 3 of MHD BLFSS.
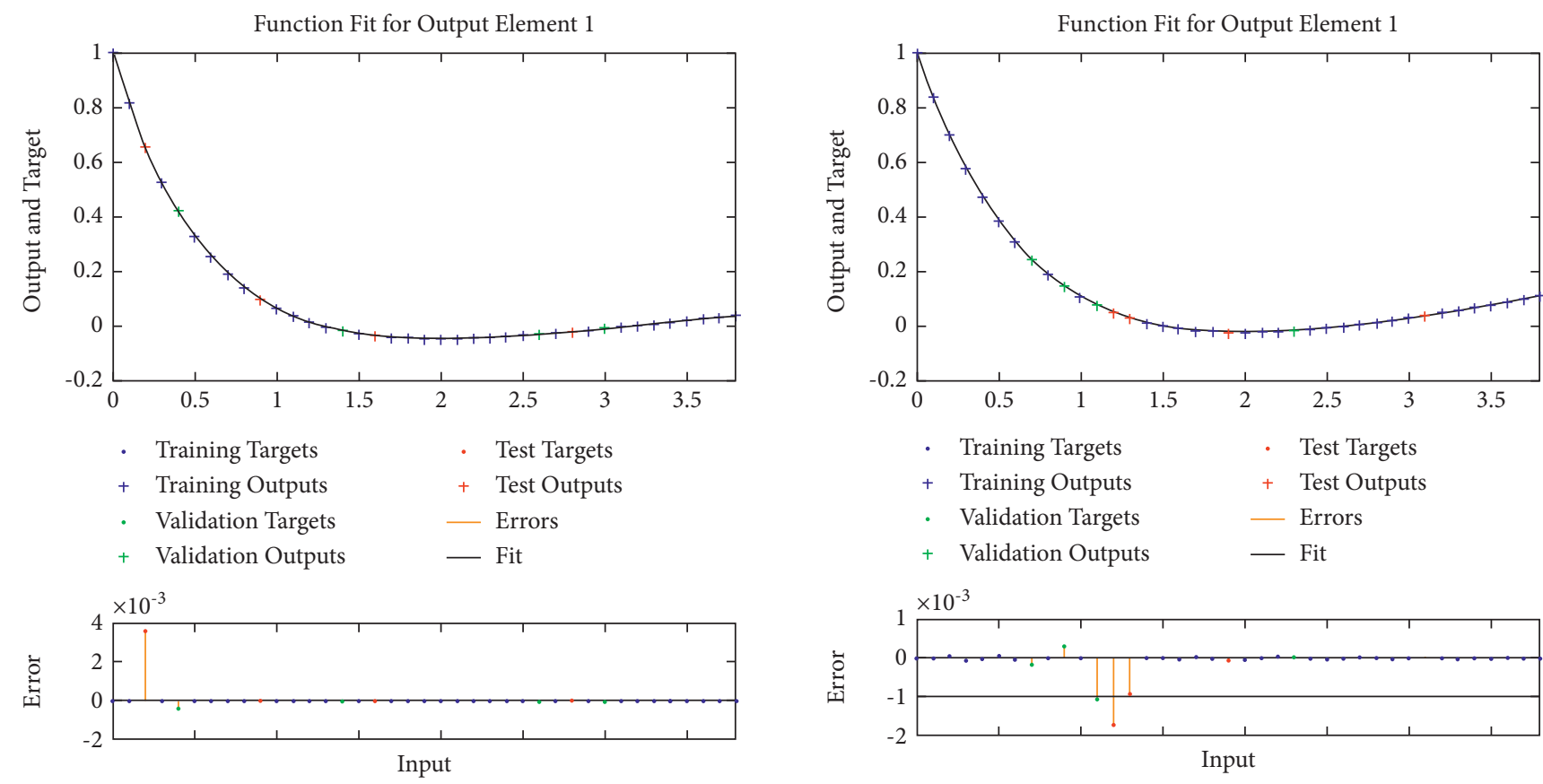

- Targets - Outputs

FIgURE 12: Comparison of NN-BLMS result with reference solution for case 1 of scenario 4 of MHD BLFSS.

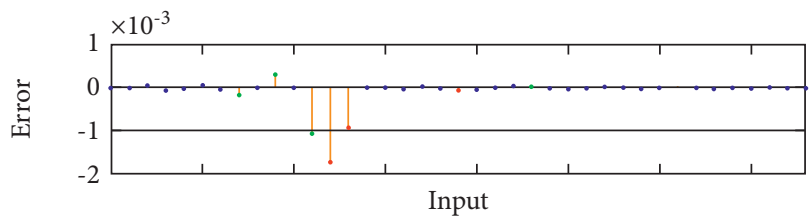

- Targets - Outputs

FIgURE 13: Comparison of NN-BLMS result with reference solution for case 3 of scenario 4 of MHD BLFSS. 


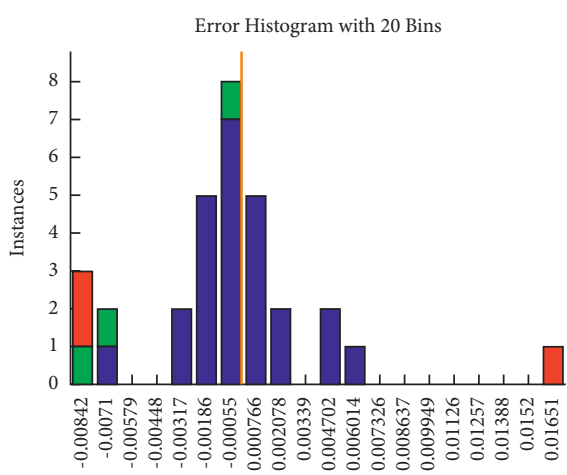

Errors $=$ Targets - Outputs

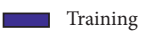

$\square$ Validation

(a)

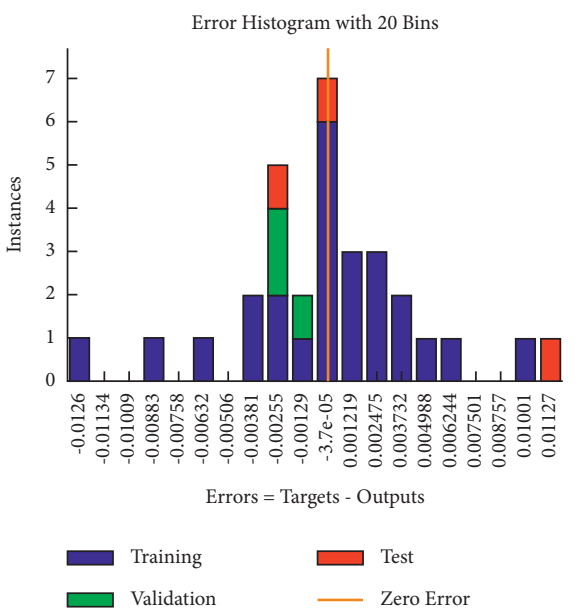

(c)

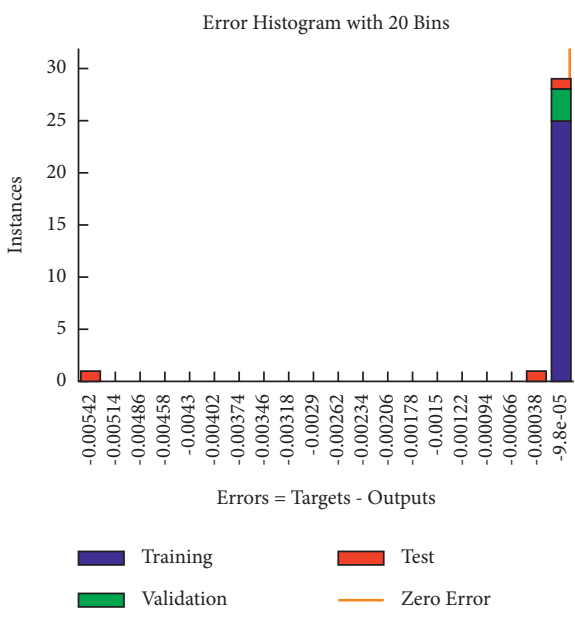

(b)

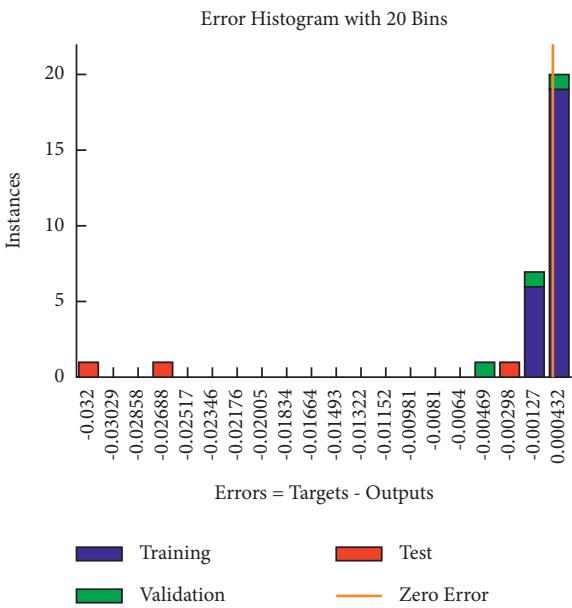

(d)

Figure 14: Continued. 


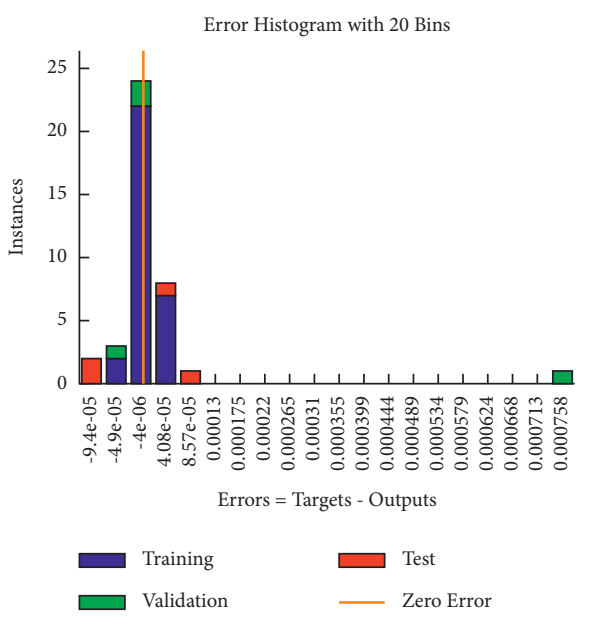

(e)

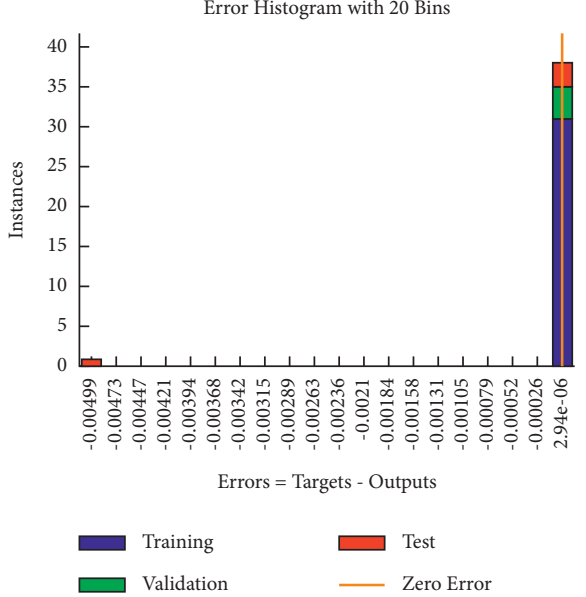

(g)

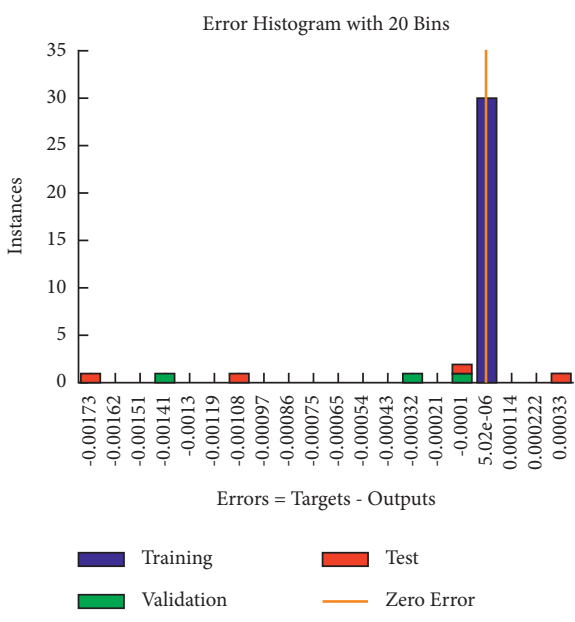

(f)

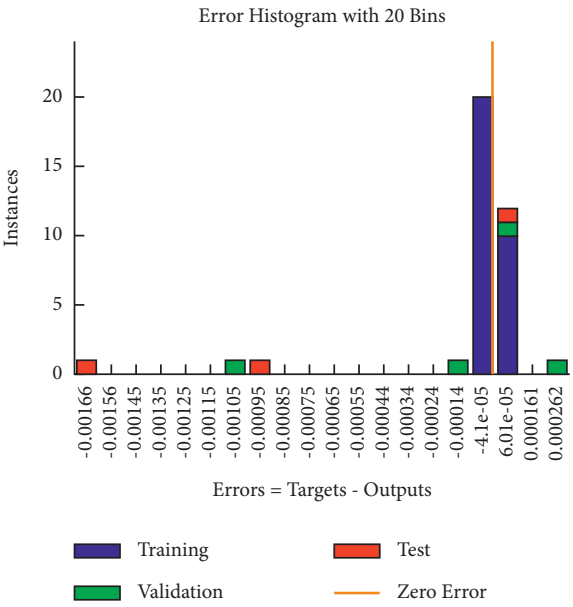

(h)

Figure 14: Error histogram studies for NN-BLMS result for cases 1 and 3 of scenarios 1-4. (a) Error histogram: case 1 of scenario 1. (b) Error histogram: case 3 of scenario 1. (c) Error histogram: case 1 of scenario 2. (d) Error histogram: case 3 of scenario 2. (e) Error histogram: case 1 of scenario 3. (f) Error histogram: case 3 of scenario 3. (g) Error histogram: case 1 of scenario 4. (h) Error histogram: case 3 of scenario 4 . 

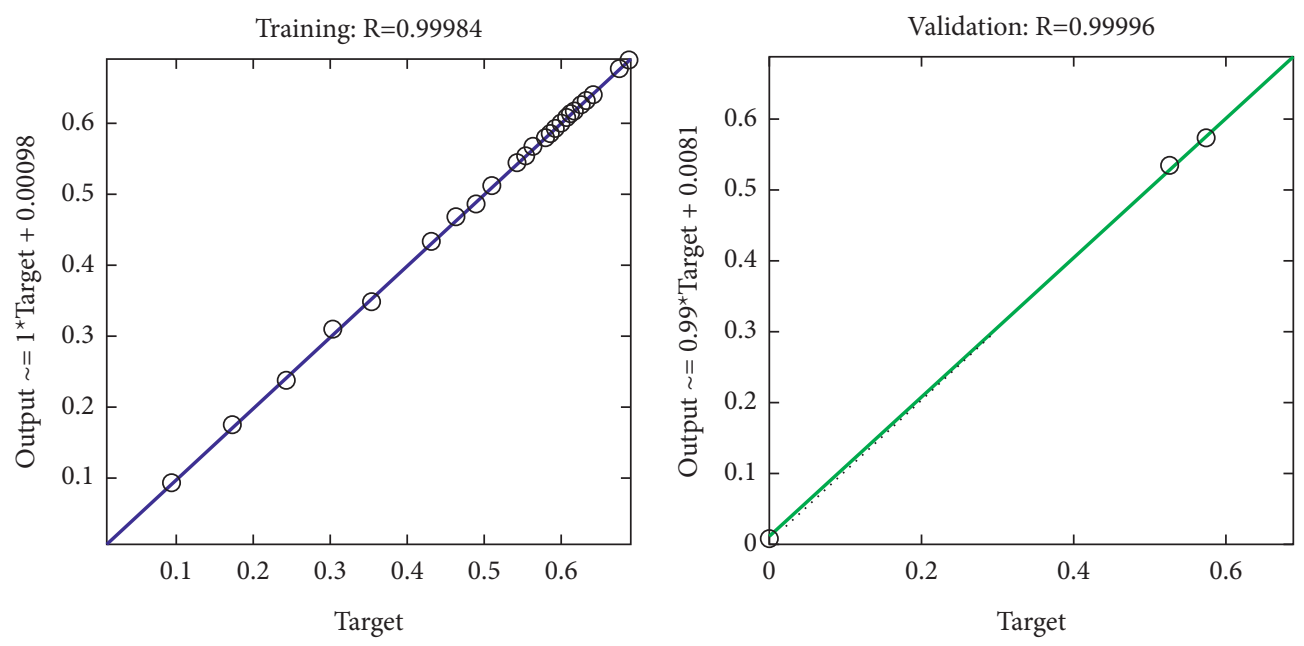

O Data

$$
\begin{array}{ll}
\text { Data } \\
-\quad \text { Fit } \\
\ldots \ldots . \mathrm{Y}=\mathrm{T}
\end{array}
$$$$
\text { — Fit }
$$$$
\text { … } \mathrm{Y}=\mathrm{T}
$$
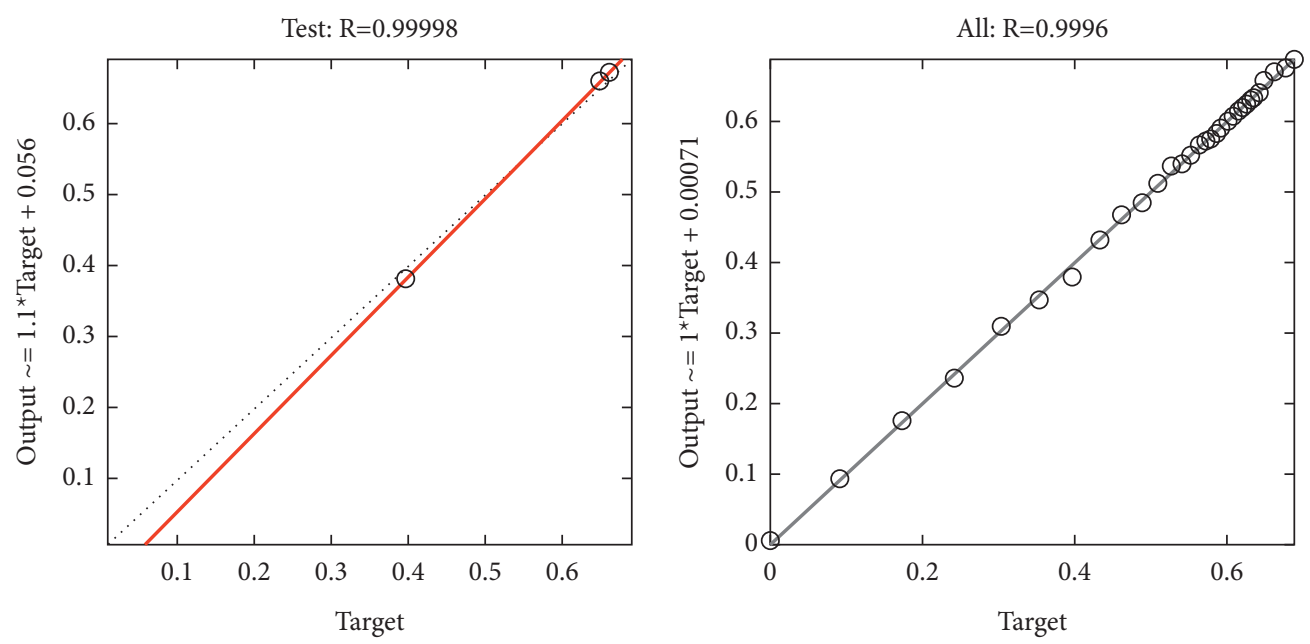
O Data
O Data
— Fit
— Fit
$\mathrm{Y}=\mathrm{T}$
…. $\mathrm{Y}=\mathrm{T}$

FIGURE 15: Regression illustrations for NN-BLMS result for case 1 of scenario 1 of MHD BLFSS. 

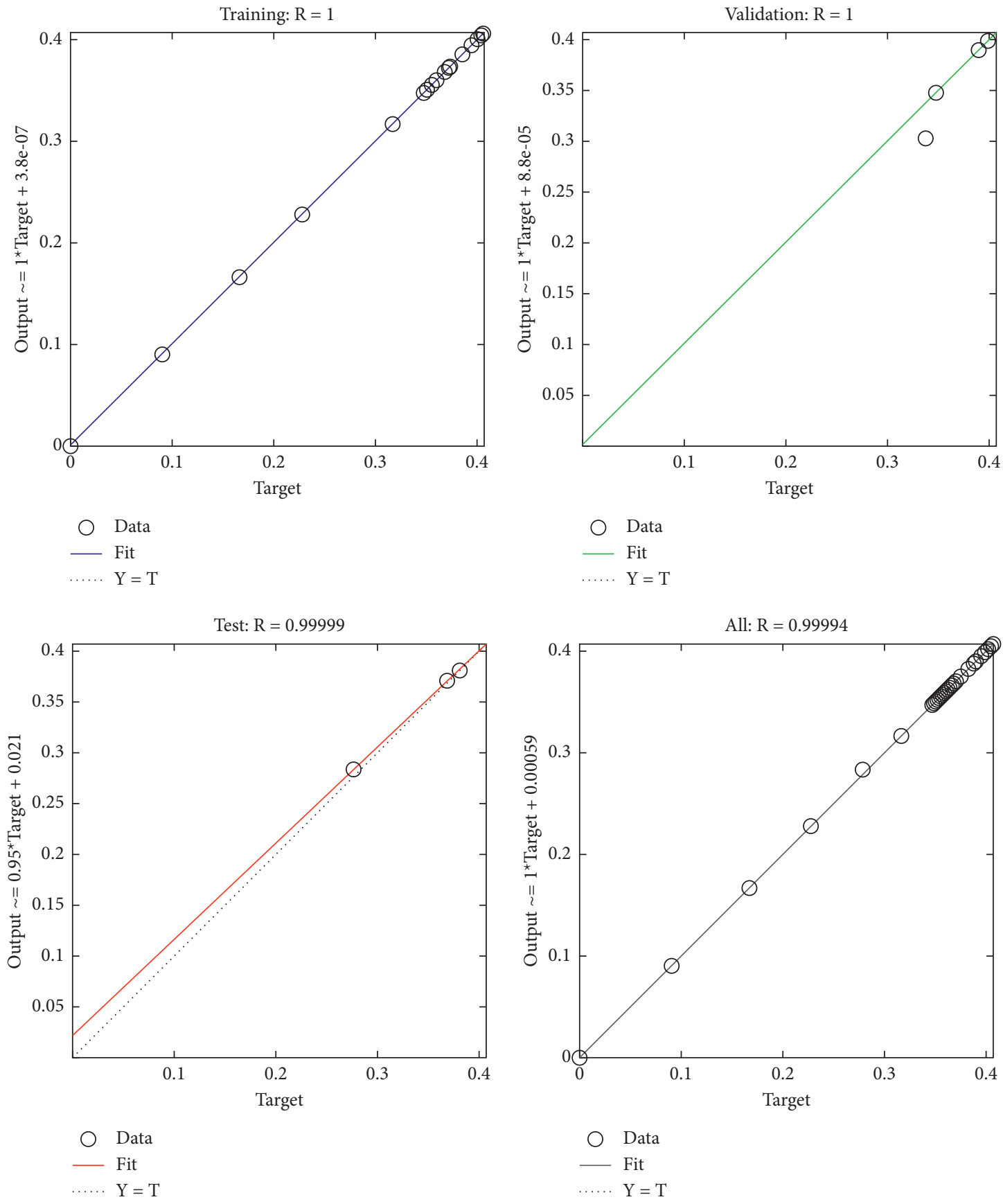

Data
-

… $\mathrm{Y}=\mathrm{T}$

FIgURE 16: Regression illustrations for NN-BLMS result for case 3 of scenario 1 of MHD BLFSS. 

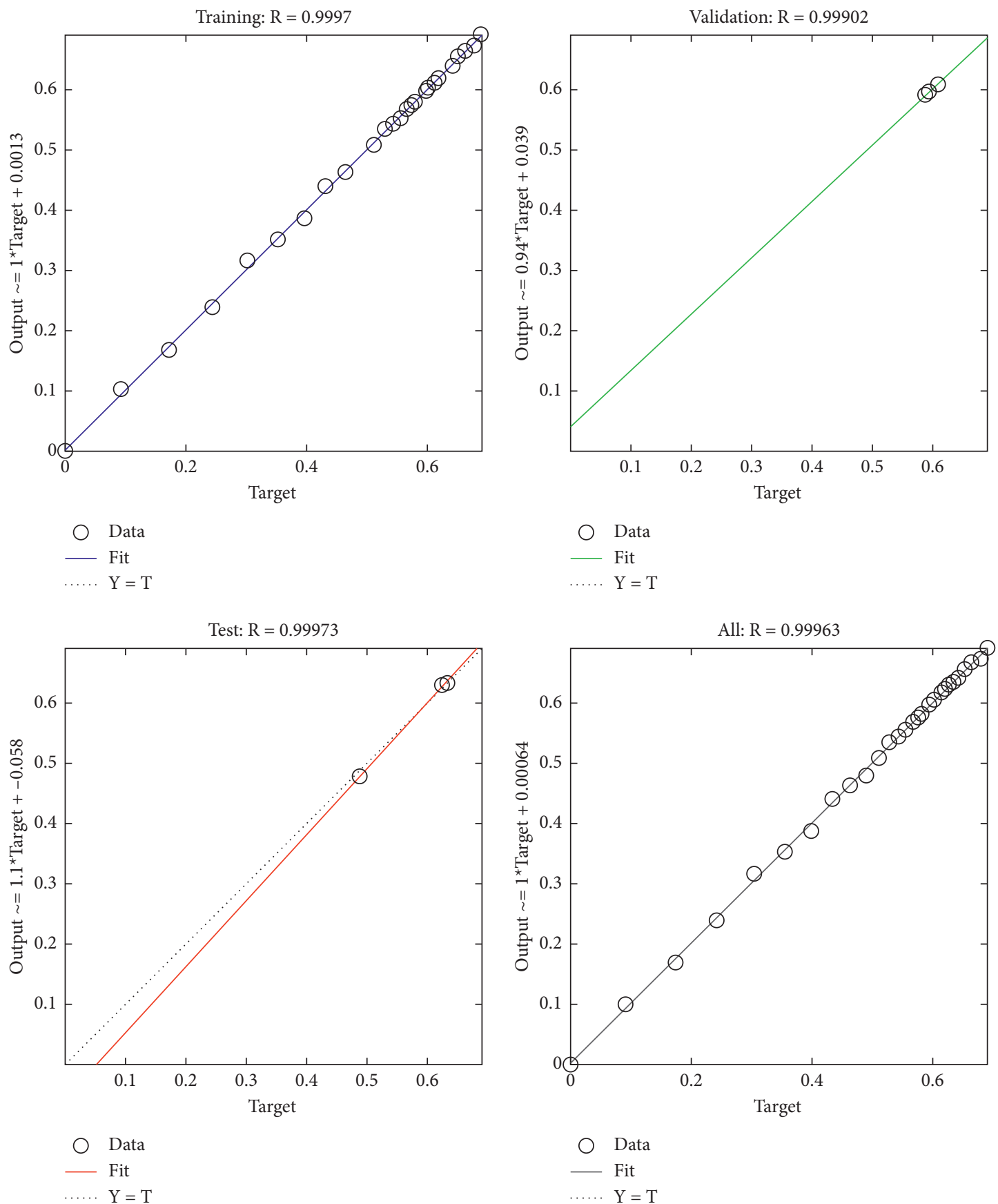

FIgURE 17: Regression illustrations for NN-BLMS result for case 1 of scenario 2 of MHD BLFSS. 

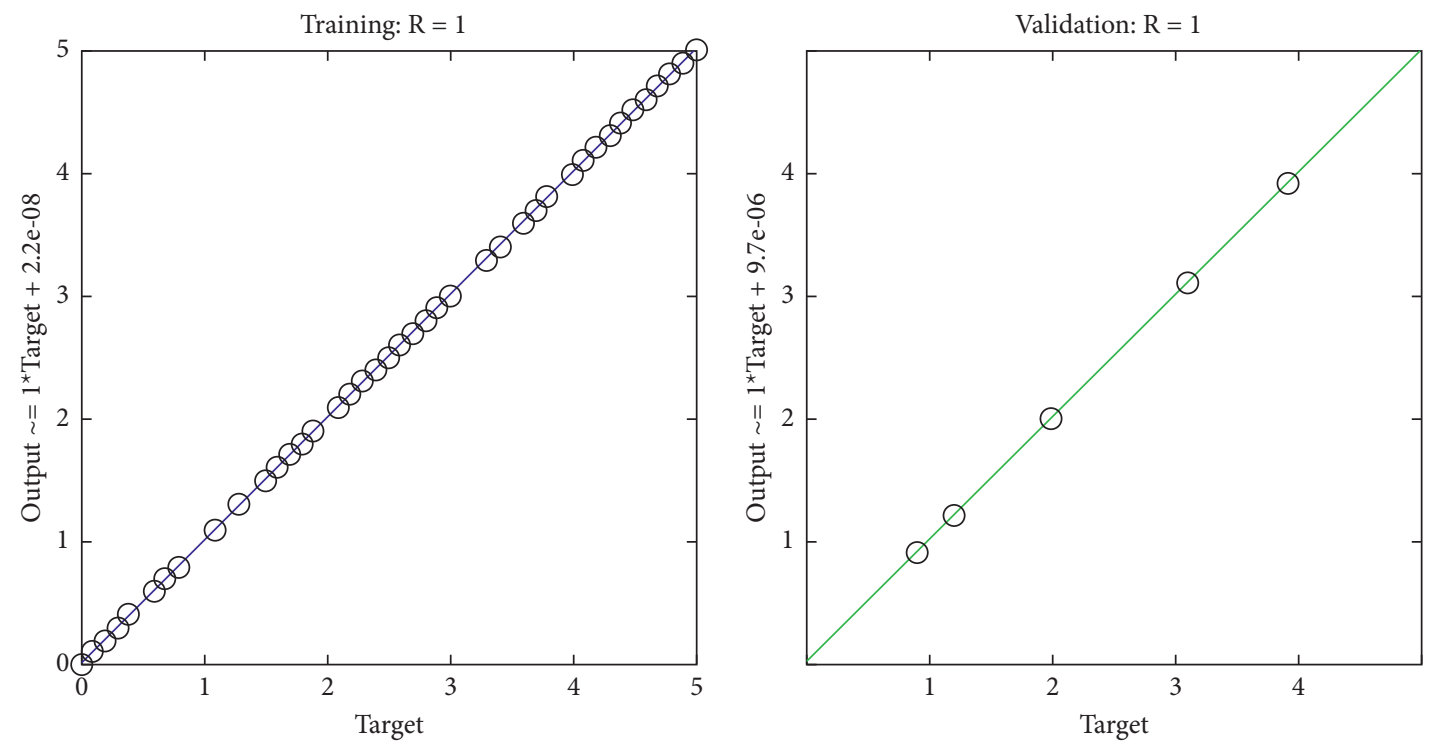

O Data

O Data

- Fit

…. $\mathrm{Y}=\mathrm{T}$

- Fit

… $\mathrm{Y}=\mathrm{T}$
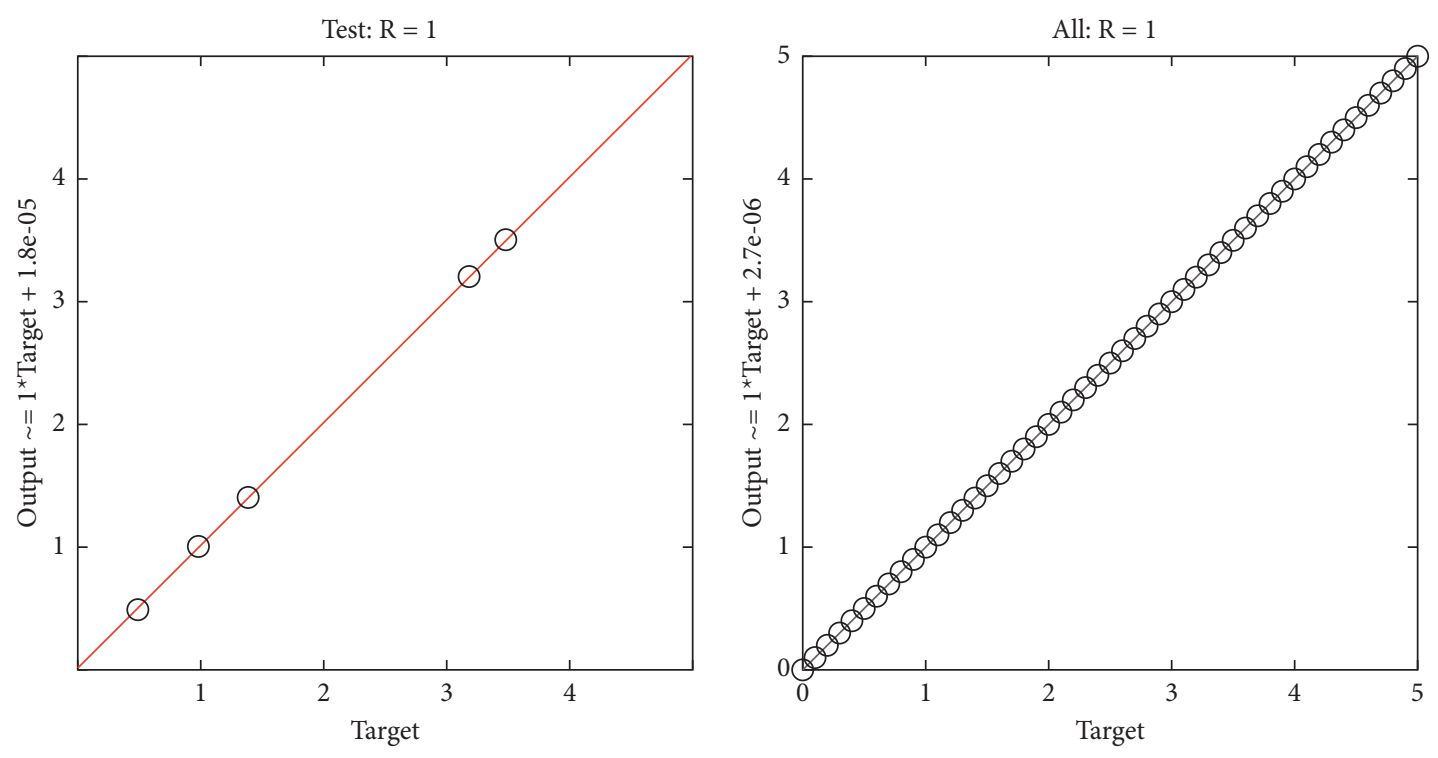

O Data

Data

- Fit

Fit

… $\mathrm{Y}=\mathrm{T}$

… $\mathrm{Y}=\mathrm{T}$

FIgURE 18: Regression illustrations for NN-BLMS result for case 3 of scenario 2 of MHD BLFSS. 

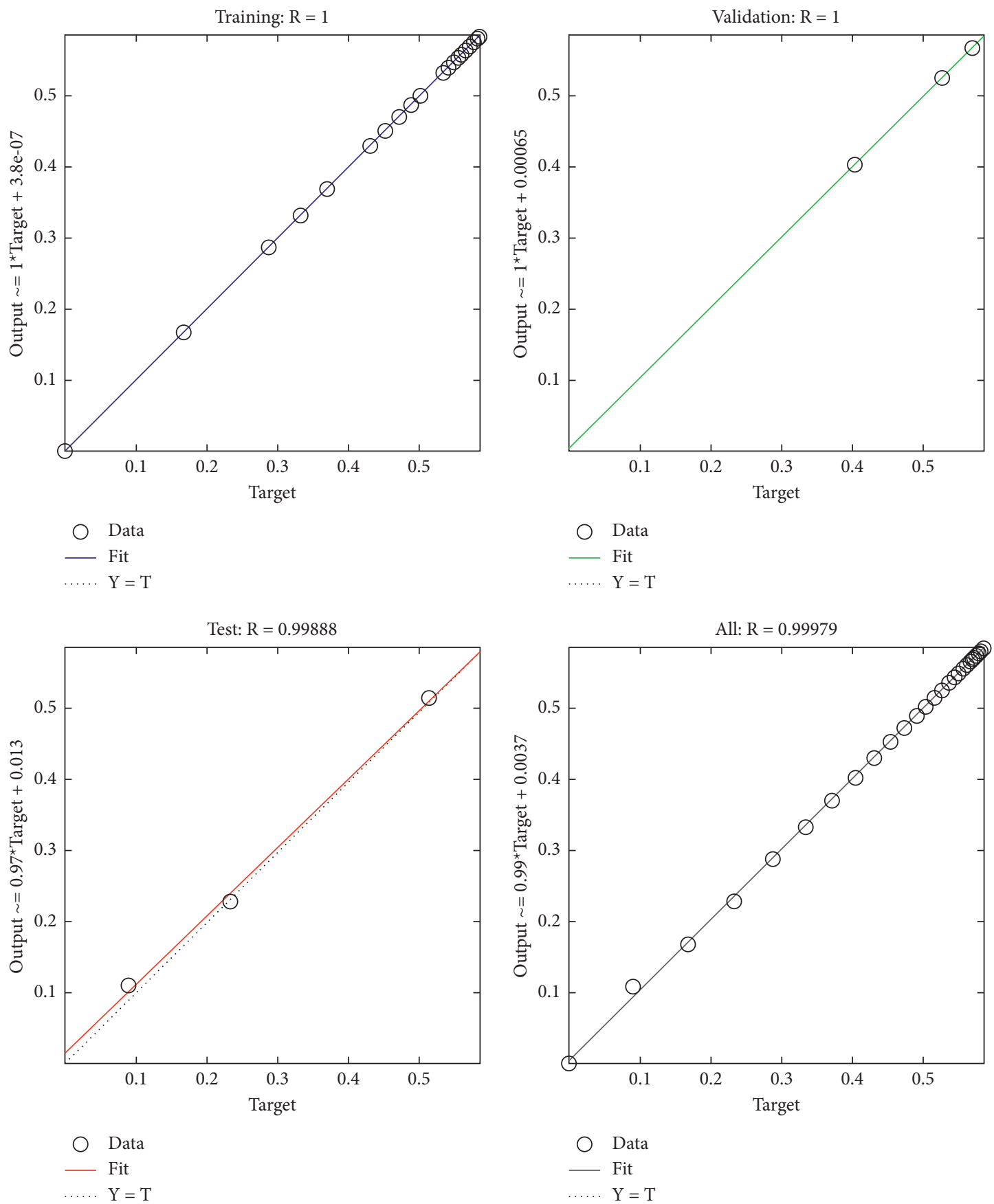

FIGURE 19: Regression illustrations for NN-BLMS result for case 1 of scenario 3 of MHD BLFSS. 

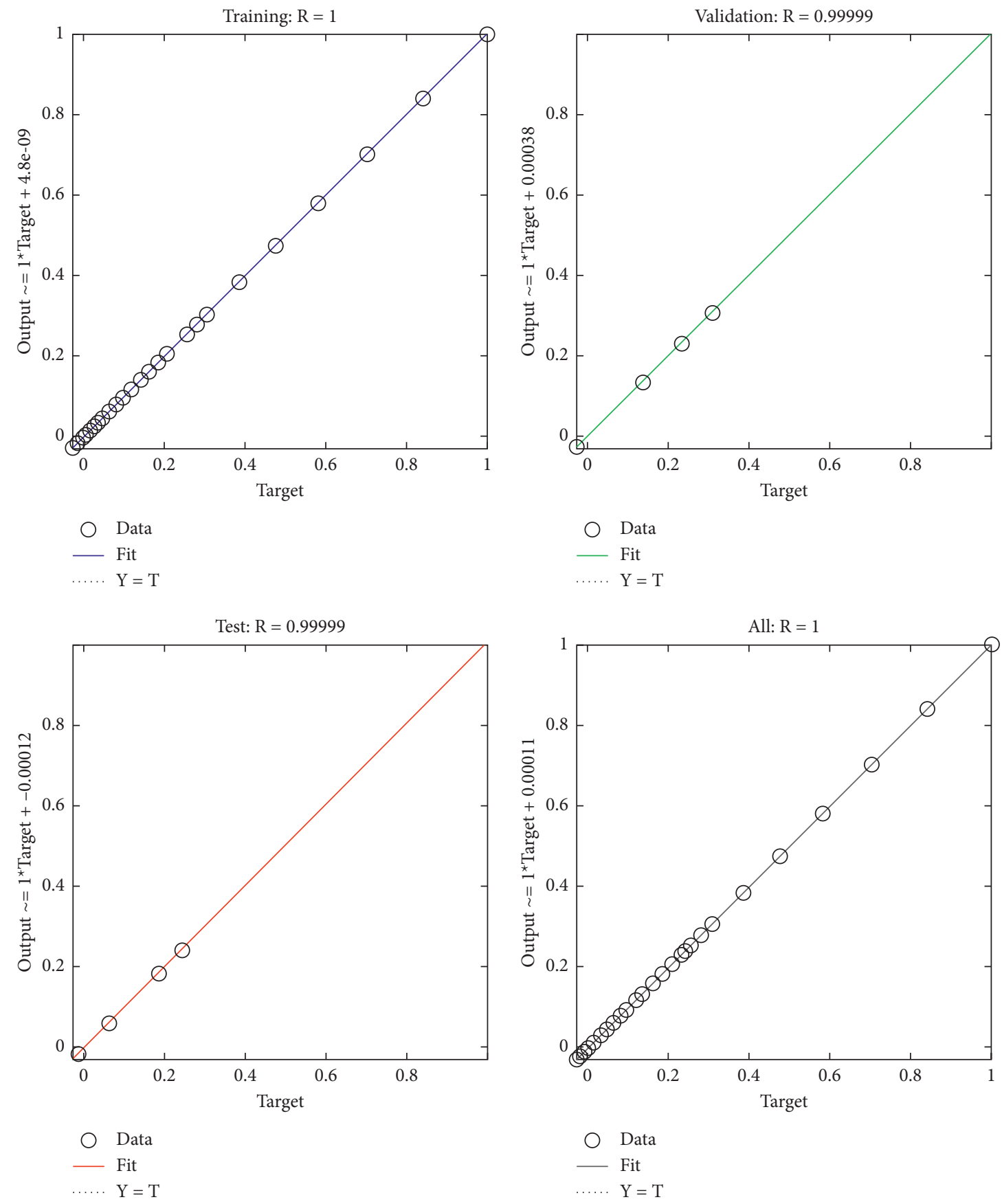

FIgURE 20: Regression illustrations for NN-BLMS result for case 3 of scenario 3 of MHD BLFSS. 

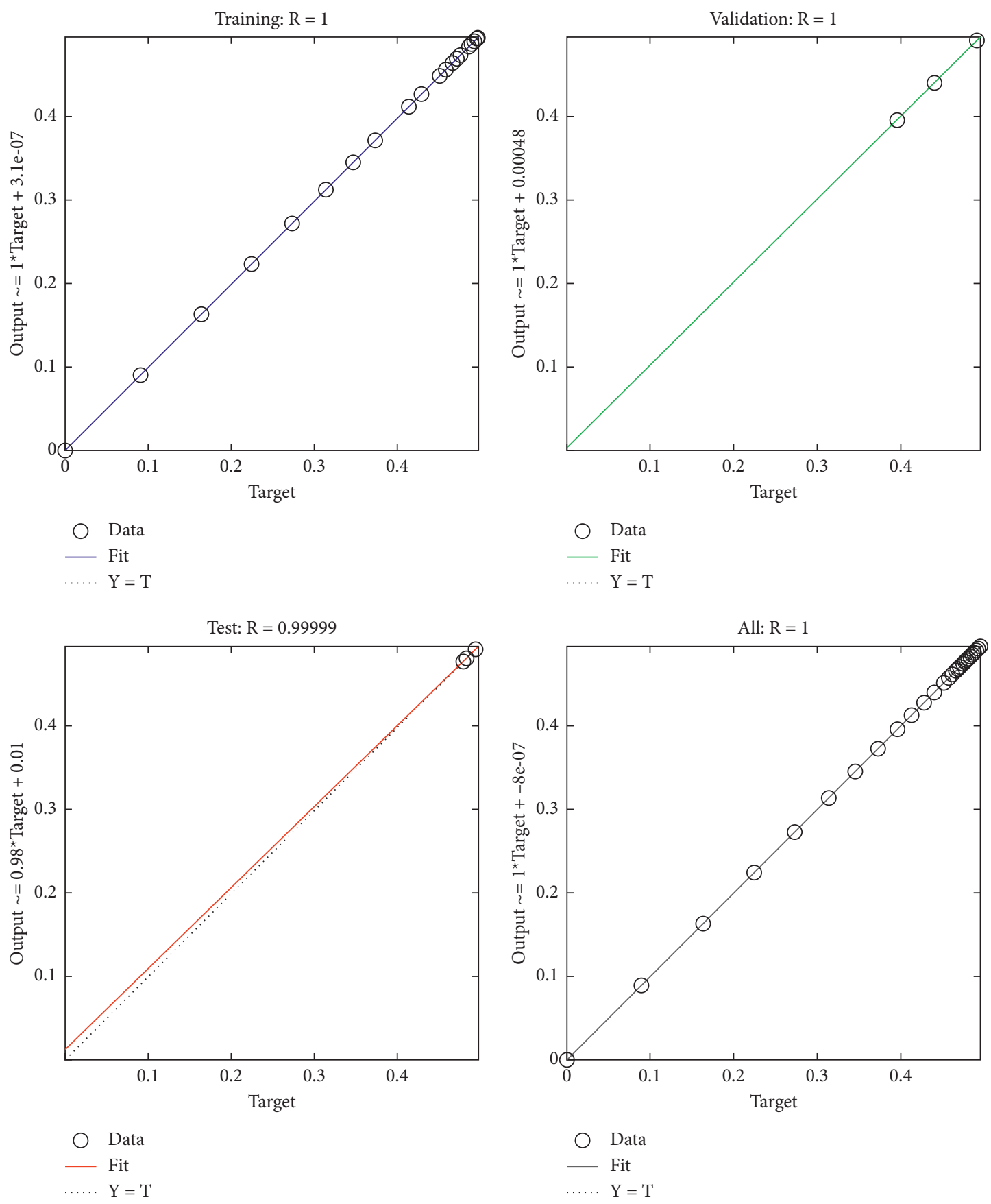

FIgURE 21: Regression illustrations for NN-BLMS result for case 1 of scenario 4 of MHD BLFSS. 

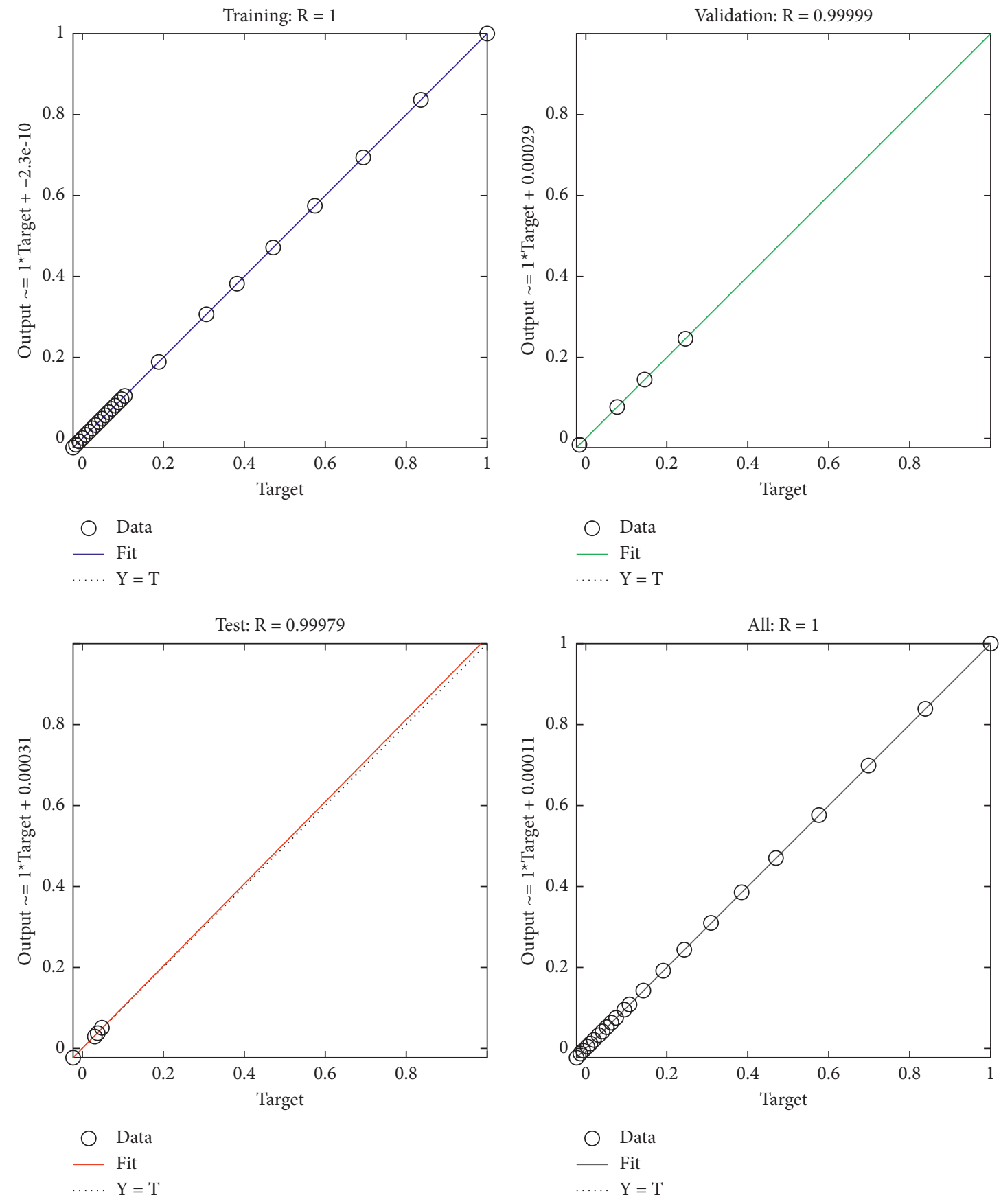

FIgURE 22: Regression illustrations for NN-BLMS result for case 3 of scenario 4 of MHD BLFSS.

TABLE 2: Results of NN-BLMS for all scenarios of MHD boundary layer flow.

\begin{tabular}{|c|c|c|c|c|c|c|c|c|}
\hline \multirow{2}{*}{ Sen 1 case } & \multicolumn{3}{|c|}{ Mean square error } & \multirow{2}{*}{ Performance } & \multirow{2}{*}{ Gradient } & \multirow{2}{*}{$\mathrm{Mu}$} & \multirow{2}{*}{ Epoch } & \multirow{2}{*}{ Time } \\
\hline & Training & Validation & Testing & & & & & \\
\hline 1 & $7.78496 E-6$ & $3.48513 E-5$ & $1.4815 E-4$ & $9.54 E-7$ & $1.00 E-07$ & $1.00 E-09$ & 12 & $<1$ \\
\hline 2 & $1.12825 E-6$ & $2.41437 E-6$ & $4.0604 E-4$ & $5.00 E-9$ & $1.27 E-07$ & $1.00 E-011$ & 13 & $<1$ \\
\hline 3 & $1.4067 E-12$ & $1.30713 E-9$ & $1.0364 E-5$ & $1.41 E-12$ & $9.95 E-08$ & $1.00 E-011$ & 153 & $<1$ \\
\hline \multicolumn{9}{|l|}{ Sen 2 case } \\
\hline 1 & $2.078 E-05$ & $4.2949 E-06$ & $5.040 E-05$ & $7.79 E-07$ & $1.68 E-05$ & $1.00 E-08$ & 9 & $<1$ \\
\hline 2 & $3.494 E-05$ & $1.6595 E-06$ & $4.323 E-05$ & $3 E-10$ & $1.45 E-05$ & $1.00 E-10$ & 12 & $<1$ \\
\hline 3 & $6.130 E-05$ & $7.7458 E-06$ & $5.980 E-05$ & $3.56 E-10$ & $2.37 E-05$ & $1.00 E-10$ & 13 & $<1$ \\
\hline
\end{tabular}


TABle 2: Continued.

\begin{tabular}{|c|c|c|c|c|c|c|c|c|}
\hline \multirow{2}{*}{ Sen 1 case } & \multicolumn{3}{|c|}{ Mean square error } & \multirow{2}{*}{ Performance } & \multirow{2}{*}{ Gradient } & \multirow{2}{*}{$\mathrm{Mu}$} & \multirow{2}{*}{ Epoch } & \multirow{2}{*}{ Time } \\
\hline & Training & Validation & Testing & & & & & \\
\hline \multicolumn{9}{|l|}{ Sen 3 case } \\
\hline 1 & $3.70 E-10$ & $1.527 E-07$ & $7.261 E-06$ & $3.7 E-10$ & $9.97 E-08$ & $1.00 E-08$ & 479 & $<1$ \\
\hline 2 & $3.387 E-10$ & $5.572 E-09$ & $6.568 E-09$ & $3.31 E-10$ & $9.99 E-08$ & $1.00 E-08$ & 494 & $<0.5$ \\
\hline 3 & $7.531 E-10$ & $5.333 E-09$ & $1.137 E-09$ & $7.53 E-11$ & $9.17 E-08$ & $1.00 E-09$ & 397 & $<0.5$ \\
\hline \multicolumn{9}{|l|}{ Sen 4 case } \\
\hline 1 & $2.91467 E-11$ & $3.5794 E-08$ & $3.2101 E-06$ & $2.91 E-11$ & $9.99 E-08$ & $1.00 E-09$ & 440 & $<0.5$ \\
\hline 2 & $3.3877 E-10$ & $5.5722 E-9$ & $6.5688 E-06$ & $3.39 E-10$ & $9.99 E-08$ & $1.00 E-09$ & 494 & $<0.5$ \\
\hline 3 & $6.4273 E-10$ & $3.0440 E-10$ & $9.3666 E-07$ & $6.43 E-10$ & $9.98 E-08$ & $1.00 E-09$ & 611 & $<0.5$ \\
\hline
\end{tabular}

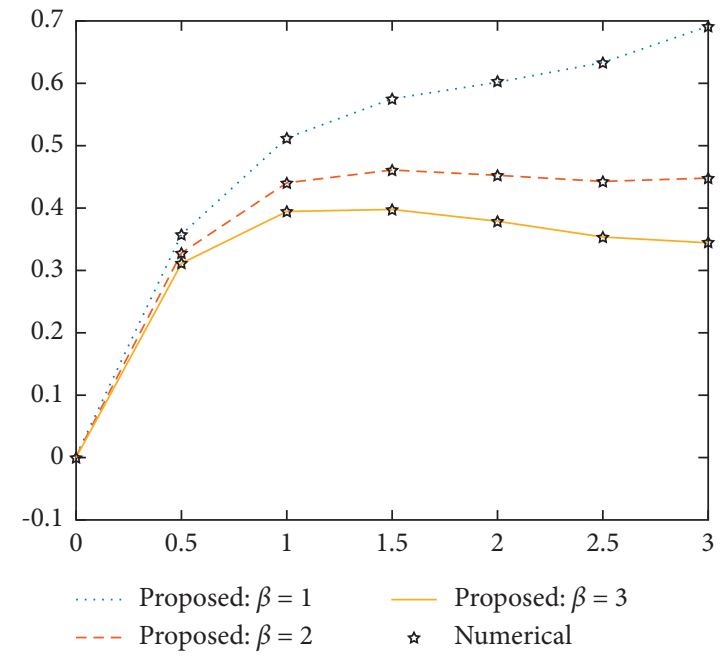

(a)

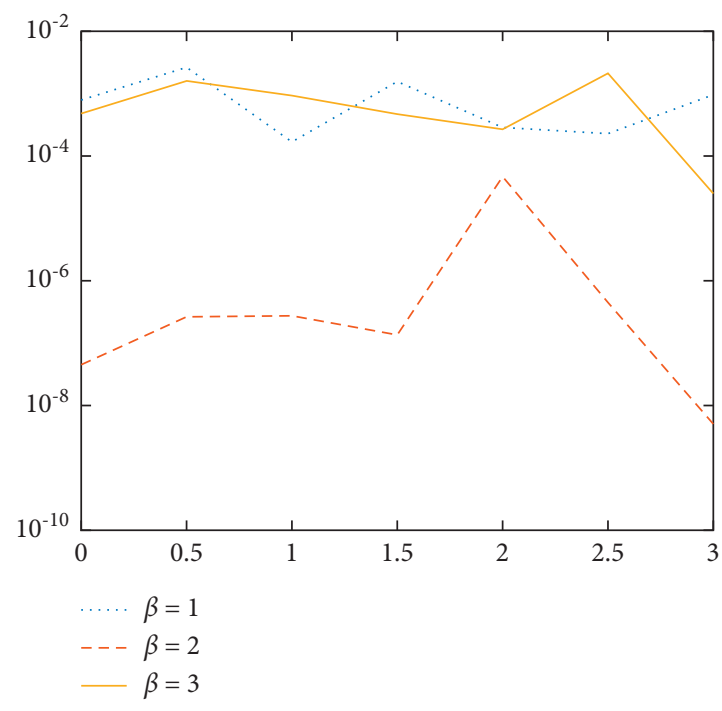

(b)

FIGURE 23: Comparison between proposed NN-BLMM with reference numerical results for scenario 1 of MHD BLFSS. (a) Variation of beta. (b) Analysis on AE.

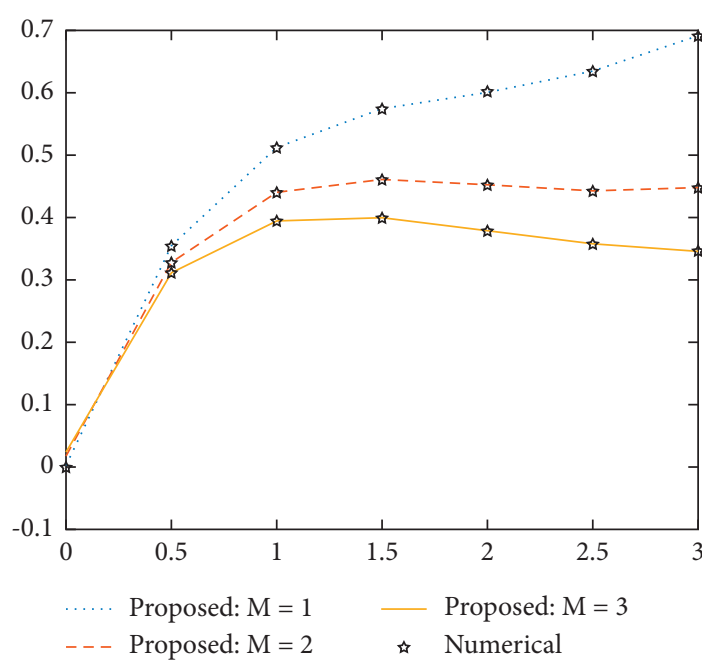

(a)

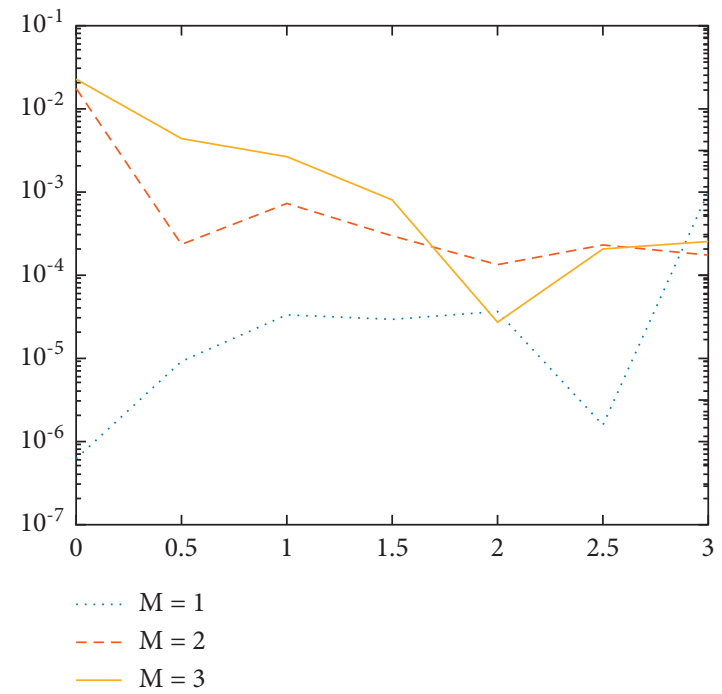

(b)

FIGURE 24: Comparison between proposed NN-BLMM with reference numerical results for scenario 2 of MHD BLFSS. (a) Variation of $M$. (b) Analysis on AE. 


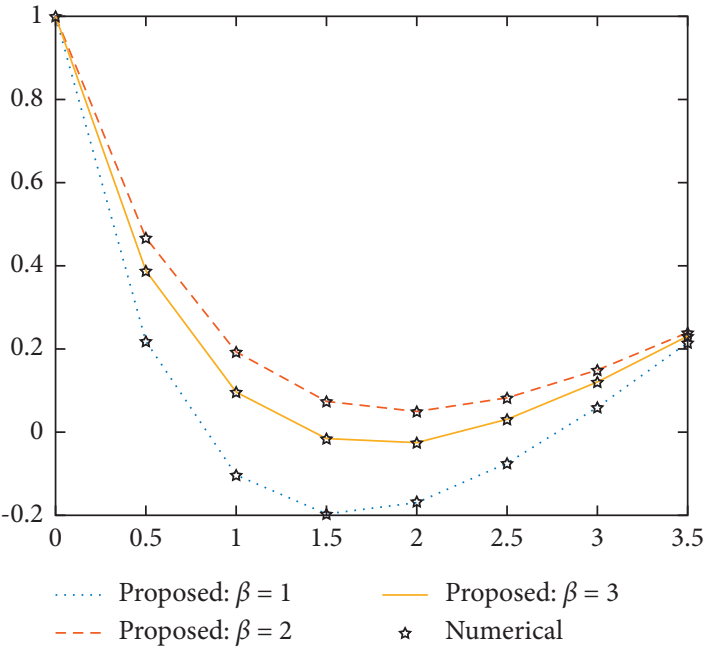

(a)

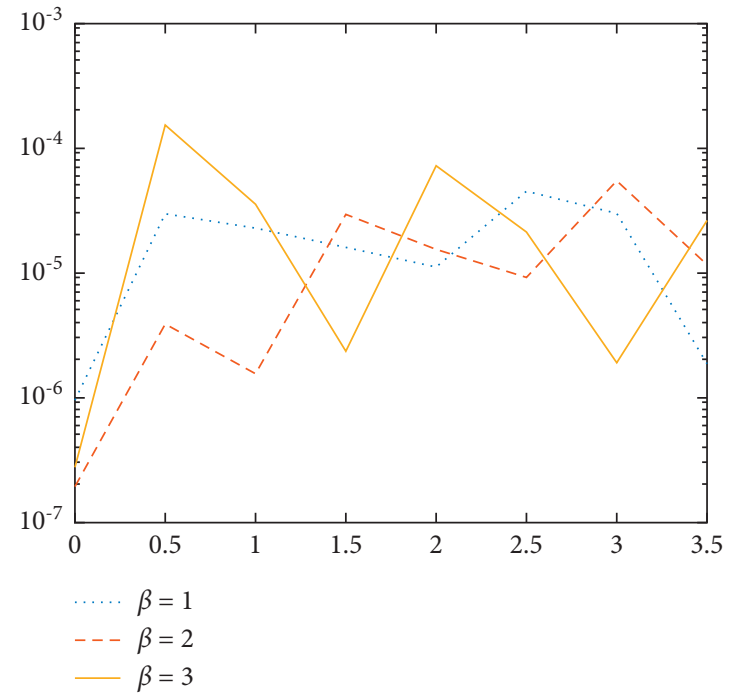

(b)

FIGURE 25: Comparison between proposed NN-BLMM with reference numerical results for scenario 3 of MHD BLFSS. (a) Variation of beta. (b) Analysis on AE.

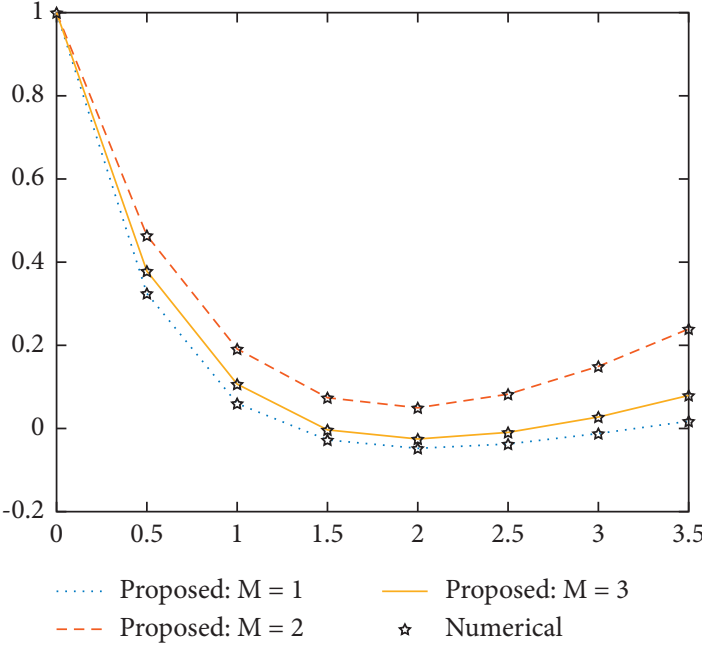

(a)

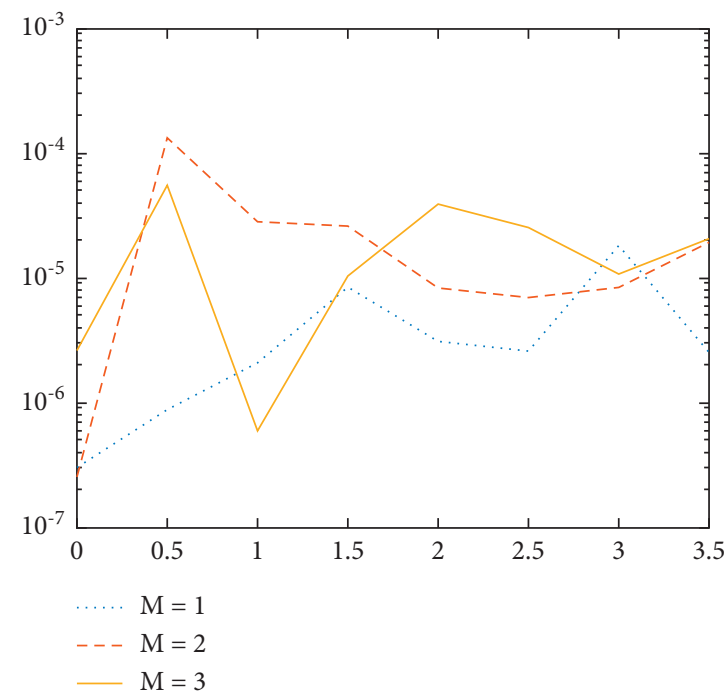

(b)

FIGURE 26: Comparison between proposed NN-BLMM with reference numerical results for scenario 4 of MHD BLFSS. (a) Variation of $M$. (b) Analysis on AE.

TABLE 3: Comparsion of results of OHAM and NN-BLMM along with absolute errors: OHAM results [56]; MOHAM [56]; NN-BLMM results.

\begin{tabular}{|c|c|c|c|c|c|c|c|c|}
\hline$\eta$ & $\begin{array}{l}f(\eta) \\
\beta=1,\end{array}$ & $\begin{array}{l}f(\eta) \\
M=2\end{array}$ & $\begin{array}{l}f(\eta) \\
\beta=1,\end{array}$ & $\begin{array}{l}f(\eta) \\
M=2\end{array}$ & $\begin{array}{l}f(\eta) \\
\beta=1,\end{array}$ & $\begin{array}{l}f(\eta) \\
M=2\end{array}$ & Absolute errors $\beta=1$, & Absolute errors $M=2$, \\
\hline 0.0 & 0.0 & 0.0 & 0.0 & 0.0 & 0.0 & 0.0 & 0.0 & 0.0 \\
\hline 0.25 & 0.187589 & 0.186587 & 0.187589 & 0.186587 & 0.187589 & 0.186587 & $2.145872 E-15$ & $1.245635 E-15$ \\
\hline 0.5 & 0.279172 & 0.271245 & 0.279172 & 0.271245 & 0.279172 & 0.271245 & $3.001245 E-15$ & $2.124586 E-15$ \\
\hline 0.75 & 0.307801 & 0.306587 & 0.307801 & 0.306587 & 0.307801 & 0.306587 & $0.124578 E-15$ & $1.854756 E-15$ \\
\hline 1.0 & 0.296615 & 0.295467 & 0.296615 & 0.295467 & 0.296615 & 0.295467 & $1.002145 E-15$ & $2.548756 E-15$ \\
\hline 1.25 & 0.262061 & 0.265468 & 0.262061 & 0.265468 & 0.262061 & 0.265468 & $1.002145 E-16$ & $6.325486 E-16$ \\
\hline 1.5 & 0.215993 & 0.212145 & 0.215993 & 0.212145 & 0.215993 & 0.212145 & $2.000458 E-16$ & $1.548796 E-16$ \\
\hline 1.75 & 0.167061 & 0.166548 & 0.167061 & 0.166548 & 0.167061 & 0.166548 & $1.003546 E-17$ & $1.254862 E-17$ \\
\hline 2.0 & 0.121651 & 0.125246 & 0.121651 & 0.125246 & 0.121651 & 0.125246 & $1.879631 E-17$ & $1.658752 E-17$ \\
\hline 2.25 & 0.084524 & 0.085478 & 0.084524 & 0.085478 & 0.084524 & 0.085478 & $5.124569 E-18$ & $2.154856 E-18$ \\
\hline 2.5 & 0.059257 & 0.059254 & 0.059257 & 0.059254 & 0.059257 & 0.059254 & $1.021022 E-19$ & $3.265478 E-19$ \\
\hline 2.75 & 0.048559 & 0.048458 & 0.048559 & 0.048458 & 0.048559 & 0.048458 & $1.054632 E-19$ & $1.658962 E-19$ \\
\hline 3.0 & 0.054407 & 0.054546 & 0.054407 & 0.054546 & 0.054407 & 0.054546 & $1.875962 E-20$ & $1.897563 E-20$ \\
\hline
\end{tabular}




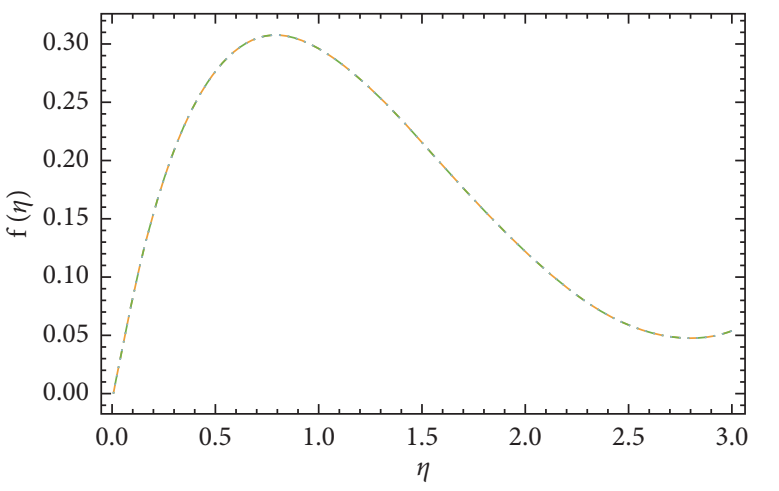

OHAM

$$
\begin{aligned}
& \text { - - - MOHAM } \\
& \text {. - - Numerical }
\end{aligned}
$$

Figure 27: Comparison of solutions.

method. In future, we may apply this method to recent developments in nanotechnology, energy, and biological model like COVID-19 etc.

In order to validate the efficiency and accuracy of the new proposed method, we compare its results with the methods available in the literature like OHAM and MOHAM as given in Table 3 and Figure 27. All of these numerical and graphical diagrams ensure the precise, flexible, and robust functionality of the NN-BLMS for the MHD boundary layer flow over a stretching sheet.

\section{Conclusions}

The computational strength in terms of the supervised learning method NN-BLMS is exploited to obtain a numerical solution for the MHD boundary layer flow over a stretching sheet after the transformation of PDEs based on the flow model into a system of ODEs by using similarity variable conversions. The optimal homotopy asymptotic method is used for the present dataset for the flow model. The data containing training, testing, and validation for NNBLMS depending on various scenarios are determined by $80 \%, 10 \%$, and $10 \%$, respectively. The close agreement of both proposed and a reference result is $10^{-2}$ to $10^{-8}$. This means that the proposed model provides highly accurate results for the fluidic system under consideration. The efficacy and performance of the proposed NN-BLMT for the solution of the flow model appears via mean squared error functions, performance measures, regression metrics, and histograms. Some of the key points are given as follows:

NN-BLMS contains less computational work and do not required linearization and is fastly convergent.

NN-BLMS is simple in applicability.

NN-BLMS has better PF as compared to other numerical methods.

NN-BLMS minimizes the absolute error.

The correctness of NN-BLMS is authenticated by MSC, EH, RG, AE, FT, PF, TS, and TR.
NN-BLMS uses $80 \%, 10 \%$ and $10 \%$ of the reference data are used as a TR, TS, and VL.

Also, the physical variation of the parameters indicates that the boundary layer thickness decreases by increasing the Deborah, porosity, and magnetic parameters.

The boundary layer flows have many applications in engineering and industries such as in the aerodynamic extrusion of a polymer sheet from a die, hot rolling, the cooling of an infinite metallic plate in a cooling bath, the boundary layer along a liquid film in condensation process, and glass-fiber production.

The conducting boundary layer flows have industrial and engineering applications such as MHD power generation, MHD generators, and MHD pumps productions.

This procedure will be used for the nanofluid flow problems and nanotechnology.

In future, the new types of platforms based on artificial intelligence will be developed for the flow problems.

\section{Nomenclature and SI units}

\author{
$a, b, c:$ Constants. \\ $\widetilde{\mathrm{B}}$ : $\quad$ Magnetic field $\left(\mathrm{NmA}^{-1}\right)$. \\ $\widetilde{\mathrm{E}}: \quad$ Electric field intensity $\left(\mathrm{NC}^{-1}\right)$. \\ $\widehat{F}_{1}, \widehat{F}_{2}$ : Homotopic functions. \\ $h$ : $\quad$ Distance between the plates $(\mathrm{m})$. \\ M: $\quad$ Magnetic parameter \\ $\beta$ : $\quad$ Boundary layer parameter \\ $O: \quad$ Origen. \\ $P: \quad$ Fluid pressure $(\mathrm{Pa})$. \\ $T: \quad$ Fluid temperature (K) \\ $u, v w$ : Velocities components $\left(\mathrm{ms}^{-1}\right)$. \\ $u_{w}$ : Stretching velocity $\left(\mathrm{ms}^{-1}\right)$. \\ $x, y, z$ : Coordinates \\ $X, Y: \quad$ Topological space \\ $\alpha: \quad$ Thermal diffusivity $\left(\mathrm{m}^{2} \mathrm{~s}^{-1}\right)$. \\ $\eta$ : $\quad$ Similarity variable. \\ $\mu$ : $\quad$ Dynamic viscosity $(\mathrm{mPa})$. \\ $v$ : $\quad$ Kinematic coefficient of viscosity.
}

\section{Data Availability}

All the relevant data are available in the manuscript.

\section{Conflicts of Interest}

The authors declare that they have no conflicts of interest.

\section{References}

[1] T. Alten, S. Oh, and H. Gegrl, Metal Forming Fundamentals and Applications, American Society for Metals, Metal Park, OH, USA, 1979.

[2] E. G. Fisher, Extrusion of Plastics, Wiley, New York, NY, USA, 1976. 
[3] Z. Tadmor and I. Klein, Engineering Principles of Plasticating Extrusion, Polymer Science and Engineering Series, Van Nostrand Reinhold, New York, NY, USA, 1970.

[4] B. C. Sakiadis, "Boundary-layer behavior on continuous solid surfaces: I. Boundary-layer equations for two-dimensional and axisymmetric flow," AIChE Journal, vol. 7, no. 1, pp. 26-28, 1961.

[5] B. C. Sakiadis, "Boundary-layer behavior on continuous solid surfaces: II. The boundary layer on a continuous flat surface," AIChE Journal, vol. 7, no. 2, pp. 221-225, 1961.

[6] L. J. Crane, "Flow past a stretching plate," Zeitschrift für angewandte Mathematik und Physik ZAMP, vol. 21, no. 4, pp. 645-647, 1970.

[7] P. S. Gupta and A. S. Gupta, "Heat and mass transfer on a stretching sheet with suction or blowing," Canadian Journal of Chemical Engineering, vol. 55, no. 6, pp. 744-746, 1977.

[8] H. I. Anderson, "MHD flow of a viscoelastic fluid past a stretching surface," Acta Mechanica, vol. 95, pp. 227-230, 1992.

[9] P. D. Ariel, "MHD flow of a viscoelastic fluid past a stretching sheet with suction," Acta Mechanica, vol. 105, no. 1-4, pp. 49-56, 1994.

[10] C. Y. Wang, "The three-dimensional flow due to a stretching flat surface," Physics of Fluids, vol. 27, no. 8, pp. 1915-1917, 1984.

[11] J. F. Brady and A. Acrivos, "Steady flow in a channel or tube with an accelerating surface velocity. An exact solution to the Navier-Stokes equations with reverse flow," Journal of Fluid Mechanics, vol. 112, no. 1, pp. 127-150, 1981.

[12] C. Y. Wang, "Fluid flow due to a stretching cylinder," Physics of Fluids, vol. 31, no. 3, pp. 466-468, 1988.

[13] C. Y. Wang, "Liquid film on an unsteady stretching surface," Quarterly of Applied Mathematics, vol. 48, no. 4, pp. 601-610, 1990.

[14] R. Usha and R. Sridharan, "The axisymmetric motion of a liquid film on an unsteady stretching surface," Journal of Fluids Engineering, vol. 117, no. 1, pp. 81-85, 1995.

[15] P. D. Ariel, "Computation of MHD flow due to moving boundary," Technical report MCS-2004-01, Department of Mathematical Sciences: Trinity Western University, Canada, 2004.

[16] T. D. M. A. Samuel and I. M. Hall, "On the series solution to the laminar boundary layer with stationary origin on a continuous, moving porous surface," Mathematical Proceedings of the Cambridge Philosophical Society, vol. 73, no. 1, pp. 223-229, 1973.

[17] P. D. Ariel, T. Hayat, and S. Asghar, "Homotopy perturbation method and axisymmetric flow over a stretching sheet," International Journal of Nonlinear Sciences and Numerical Stimulation, vol. 7, no. 4, pp. 399-406, 2006.

[18] M. Sheikholeslami and R. Ellahi, "Three dimensional mesoscopic simulation of magnetic field effect on natural convection of nanofluid," International Journal of Heat and Mass Transfer, vol. 89, pp. 799-808, 2015.

[19] W. Ibrahim and C. Zemedu, "Numerical solution of micropolar nanofluids with Soret, Dufor effects and multiple slip conditions," Journal of Physics Communications, vol. 4, no. 1, Article ID 015016, 2020.

[20] F. Javed and S. Nadeem, "Numerical solution of a casson nanofluid flow and heat transfer analysis between concentric cylinders," Journal of Power Technologies, vol. 99, no. 1, pp. 25-30, 2019.

[21] R. Ellahi, S. M. Sait, N. Shehzad, and Z. Ayaz, "A hybrid investigation on numerical and analytical solutions of electro- magnetohydrodynamics flow of nanofluid through porous media with entropy generation," International Journal of Numerical Methods for Heat and Fluid Flow, vol. 30, no. 2, 2019.

[22] M. Siavashi, H. Rasam, and A. Izadi, "Similarity solution of air and nanofluid impingement cooling of a cylindrical porous heat sink," Journal of Thermal Analysis and Calorimetry, vol. 135, no. 2, pp. 1399-1415, 2019.

[23] M. Subhani and S. Nadeem, "Numerical analysis of micropolar hybrid nanofluid," Applied Nanoscience, vol. 9, no. 4, pp. 447-459, 2019.

[24] M. A. Sadiq, A. U. Khan, S. Saleem, and S. Nadeem, "Numerical simulation of oscillatory oblique stagnation point flow of a magneto micropolar nanofluid," RSC Advances, vol. 9, no. 9, pp. 4751-4764, 2019.

[25] Z. Ahmed, S. Nadeem, S. Saleem, and R. Ellahi, "Numerical study of unsteady flow and heat transfer CNT-based MHD nanofluid with variable viscosity over a permeable shrinking surface," International Journal of Numerical Methods for Heat and Fluid Flow, vol. 29, no. 12, 2019.

[26] I. Ahmad, A. Z. R. Muhammad, B. Muhammad, and A. Farooq, "Neural network methods to solve the Lane-Emden type equations arising in thermodynamic studies of the spherical gas cloud model," Neural Computing \& Applications, vol. 28, no. 1, pp. 929-944, 2017.

[27] K. Hosseinzadeh, M. R. Mardani, S. Sajad, S. Salehi, M. Waqas, and D. D. Ganji, "Entropy generation of threedimensional Bödewadt flow of water and hexanol base fluid suspended by $\mathrm{Fe}_{3} \mathrm{O}_{4}$ and $\mathrm{MoS}_{2}$ hybrid nanoparticles," Pramana, vol. 95, no. 2, p. 57, 2021.

[28] Kh. Hosseinzadeh, S. Roghani, A.R. Mogharrebi, M. Waqas, and D. D. Ganji, "Investigation of cross-fluid flow containing motile gyrotactic microorganisms and nanoparticles over a three-dimensional cylinder," Alexandria Engineering Journal, vol. 59, no. 5, pp. 3297-3307, 2020.

[29] Y.-Q. Song, H. Waqas, K. Al-Khaled et al., "Bioconvection analysis for Sutter by nanofluid over an axially stretched cylinder with melting heat transfer and variable thermal features: A Marangoni and solutal model," Alexendria engineering journal, vol. 60, pp. 4663-4675, 2021.

[30] K. Hosseinzadeh, E. Montazer, M. B. Shafii, and D. D. Ganji, "Heat transfer hybrid nanofluid (1-Butanol/MoS2-Fe3O4) through a wavy porous cavity and its optimization," International Journal of Numerical Methods for Heat and Fluid Flow, vol. 31, no. 5, pp. 1547-1567, 2021.

[31] S. Salehi, N. Amin, and D. D. Ganji, "Hydrothermal analysis of MHD squeezing mixture fluid suspended by hybrid nanoparticles between two parallel plates," Case Studies in Thermal Engineering, vol. 20, Article ID 1000650, 2021.

[32] M. Gholinia, Kh. Hosseinzadeh, and D. D. Ganji, "Investigation of different base fluids suspend by CNTs hybrid nanoparticle over a vertical circular cylinder with sinusoidal radius," Case Studies in Thermal Engineering, vol. 21, Article ID 100666, 2020.

[33] Z. Sabir, A. Z. R. Muhammad, U. Muhammad, and S. Muhammad, "Design of neuro-swarming-based heuristics to solve the third-order nonlinear multi-singular Emden-Fowler equation," The European Physical Journal Plus, vol. 135, no. 6, pp. 1-17, 2020.

[34] Z. Sabir, H. A. Wahab, M. Umar, M. G. Sakar, and M. A. Z. Raja, "Novel design of Morlet wavelet neural network for solving second order Lane-Emden equation," Mathematics and Computers in Simulation, vol. 172, pp. 1-14, 2020. 
[35] A. Mehmood, Z. Aneela, S. A. Muhammad, and A. Z. R. Muhammad, "Design of Nature-Inspired Heuristic Paradigm for Systems in Nonlinear Electrical Circuits," Neural Computing and Applications, vol. 32, pp. 7121-7137, 2019.

[36] M. A. Z. Raja, A. Mehmood, S. A. Niazi, and S. M. Shah, "Computational intelligence methodology for the analysis of RC circuit modelled with nonlinear differential order system," Neural Computing \& Applications, vol. 30, no. 6, pp. 19051924, 2018.

[37] S. I. Ahmad, F. Faisal, S. Muhammad, and M. A. Z. Raja, "A new heuristic computational solver for nonlinear singular Thomas-Fermi system using evolutionary optimized cubic splines," The European Physical Journal Plus, vol. 135, no. 1, pp. 1-29, 2020.

[38] Z. Sabir, M. A. Manzar, M. A. Z. Raja, M. Sheraz, and A. M. Wazwaz, "Neuro-heuristics for nonlinear singular Thomas-Fermi systems," Applied Soft Computing, vol. 65, pp. 152-169, 2018.

[39] M. A. Z. Raja, M. Ammara, A. K. Adeel, and Z. Aneela, "Integrated Intelligent Computing for Heat Transfer and Thermal Radiation-Based Two-phase MHD Nanofluid Flow model," Neural Computing and Applications, vol. 32, no. 9, 2019.

[40] M. A. Z. Raja, F. H. Shah, M. Tariq, I. Ahmad, and S. I. Ahmad, "Design of artificial neural network models optimized with sequential quadratic programming to study the dynamics of nonlinear Troesch's problem arising in plasma physics," Neural Computing \& Applications, vol. 29, no. 6, pp. 83-109, 2018.

[41] M. A. Z. Raja, M. A. Manzar, F. H. Shah, and F. H. Shah, "Intelligent computing for Mathieu's systems for parameter excitation, vertically driven pendulum and dusty plasma models," Applied Soft Computing, vol. 62, pp. 359-372, 2018.

[42] M. A. Z. Raja, M. A. Manzar, S. M. Shah, and Y. Chen, "Integrated intelligence of fractional neural networks and sequential quadratic programming for Bagley-Torvik systems arising in fluid mechanics," Journal of Computational and Nonlinear Dynamics, vol. 15, no. 5, 2020.

[43] I. Ahmad, H. Ilyas, A. Urooj, M. S. Aslam, M. Shoaib, and M. A. Z. Raja, "Novel applications of intelligent computing paradigms for the analysis of nonlinear reactive transport model of the fluid in soft tissues and microvessels," Neural Computing \& Applications, vol. 31, no. 12, pp. 9041-9059, 2019.

[44] S. Akbar, M. A. Z. Raja, F. Zaman, T. Mehmood, and M. A. R. Khan, "Design of bio-inspired heuristic techniques hybridized with sequential quadratic programming for joint parameters estimation of electromagnetic plane waves," Wireless Personal Communications, vol. 96, no. 1, pp. 14751494, 2017.

[45] J. A. Khan, M. A. Z. Raja, M. M. Rashidi, M. I. Syam, and A. M. Wazwaz, "Nature-inspired computing approach for solving non-linear singular Emden-Fowler problem arising in electromagnetic theory," Connection Science, vol. 27, no. 4, pp. 377-396, 2015.

[46] M. A. Z. Raja, T. Ahmed, and S. M. Shah, "Intelligent computing strategy to analyze the dynamics of convective heat transfer in MHD slip flow over stretching surface involving carbon nanotubes," Journal of the Taiwan Institute of Chemical Engineers, vol. 80, pp. 935-953, 2017.

[47] M. A. Zahoor Raja, Z. Shah, M. Anwaar Manzar, I. Ahmad, M. Awais, and D. Baleanu, "A new stochastic computing paradigm for nonlinear Painlevé II systems in applications of random matrix theory," The European Physical Journal Plus, vol. 133, no. 7, Article ID 254, 2018.

[48] S. Lodhi, A. M. Muhammad, and A. Z. R. Muhammad, "Fractional neural network models for nonlinear Riccati systems," Neural Computing \& Applications, vol. 31, no. 1, pp. 359-378, 2019.

[49] A. B. Çolak, "An experimental study on the comparative analysis of the effect of the number of data on the error rate of artificial neural network," International Journal of Energy Research, vol. 45, no. 1, Article ID e5680, 2020.

[50] A. Shafiq, A. B. Çolak, T. N. Sindhu, M. A.-M. Qasem, and T. Abdeljawad, "Estimation of unsteady hydromagnetic Williamson fluid flow in a radiative surface through numerical and artificial neural network modeling," Scientific Reports, vol. 11, Article ID 14509, 2021.

[51] AB. Colak, "A novel comparative analysis between the experimental and numeric methods on viscosity of zirconium oxide nano-fluid: developing optimal artificial neural network and new mathematical model," Powder Technology, vol. 381, no. 38 , pp. $338-351,2021$.

[52] M. A. Ariana, B. Vaferi, and G. Karimi, "Prediction of thermal conductivity of alumina water-based nanofluids by artificial neural networks," Powder Technology, vol. 278, pp. 1-10, 2015.

[53] A. Shafiq, S. A. Lone, N. S. Tabassum, Q. M. Al-Mdallal, and G. Rasool, "Statistical modeling for bioconvective tangent hyperbolic nanofluid towards stretching surface with zero mass flux condition," Scientific Reports, vol. 11, no. 1, pp. 1-11, 2021.

[54] Y. Peng, MB. Ghahnaviyeh, MN. Ahamd et al., "Analysis of the effect of roughness and concentration of $\mathrm{Fe} 3 \mathrm{O} 4 /$ water nanofluid on the boiling heat transfer using the artificial neural network: an experimental and numerical study," International Journal of Thermal Sciences, vol. 163, Article ID 106863, 2021.

[55] A. Akhgar, D. Togharie, N. Sina, and M. Afrand, "Developing dissimilar artificial neural networks (ANNs) to prediction the thermal conductivity of MWCNT-TiO2/water-ethylene glycol hybrid nanofluid," Powder Technology, vol. 355, pp. 602-610, 2019.

[56] M. Fiza, S. Islam, and H. Ullah, "Analytical solution of MHD viscous flow over a stretching sheet by MOHAM," International Journal of Fluid Mechanics Research, vol. 45, no. 4, pp. 369-375, 2018. 